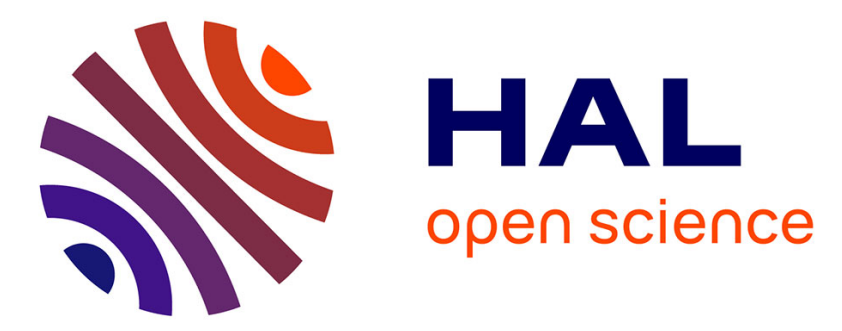

\title{
High-cycle fatigue behavior of a laser powder bed fusion additive manufactured Ti-6Al-4V titanium: effect of pores and tested volume size
}

Etienne Pessard, Manon Lavialle, Pascal Laheurte, Paul Didier, Myriam Brochu

\section{To cite this version:}

Etienne Pessard, Manon Lavialle, Pascal Laheurte, Paul Didier, Myriam Brochu. High-cycle fatigue behavior of a laser powder bed fusion additive manufactured Ti-6Al-4V titanium: effect of pores and tested volume size. International Journal of Fatigue, 2021, 149, pp.106206. 10.1016/j.ijfatigue.2021.106206 . hal-03199338

\section{HAL Id: hal-03199338 \\ https://hal.science/hal-03199338}

Submitted on 15 Apr 2021

HAL is a multi-disciplinary open access archive for the deposit and dissemination of scientific research documents, whether they are published or not. The documents may come from teaching and research institutions in France or abroad, or from public or private research centers.
L'archive ouverte pluridisciplinaire HAL, est destinée au dépôt et à la diffusion de documents scientifiques de niveau recherche, publiés ou non, émanant des établissements d'enseignement et de recherche français ou étrangers, des laboratoires publics ou privés. 


\title{
High-cycle fatigue behavior of a laser powder bed fusion additive manufactured Ti-6Al-4V titanium: effect of pores and tested volume size
}

\author{
Etienne PESSARD ${ }^{\mathrm{a}, *}$, Manon LAVIALLE ${ }^{\mathrm{a}}$, Pascal LAHEURTE ${ }^{\mathrm{b}}$, Paul DIDIER $^{\mathrm{b}}$, Myriam $^{-}$ \\ $\mathrm{BROCHU}^{\mathrm{C}}$
}

\author{
${ }^{a}$ Arts et Metiers Institure of Technology, LAMPA, HESAM Université, Angers, FRANCE \\ ${ }^{b}$ Université de Lorraine, Laboratory LEM3, Metz, FRANCE \\ ${ }^{c}$ Ecole Polytechnique de Montréal, Laboratory LAPOM, Montréal, Québec, CANADA
}

\begin{abstract}
This work is focused on the effect of natural defect on the fatigue resistance of a laser powder bed fusion additively manufactured Ti-6Al-4V titanium. To reveal the fatigue strength variability and its sensitivity to the defect size, push-pull fatigue tests have been undertaken on specimens with different sizes of highly loaded volume of material. In order to easily vary the size of the highly loaded volume, specimens containing different numbers of surface hemispherical shape holes of $600 \mu \mathrm{m}$ in diameter have been tested. This method also allowed to test small volume which triggered crack initiation from microstructural features.

The fatigue damage mechanisms observed and the average natural defect size measured on the failure surfaces depend on the size of the highly stressed region. A higher fatigue strength is observed for smaller stressed volumes and defect free regions. To reduce the impact lack-offusion on fatigue and increase the probability of triggering crack initiation from a microstructural feature, the specimens were built in the horizontal direction. For specimens where fatigue cracks initiated at natural discontinuities, the results reported in a Kitagawa-Takahashi diagram revealed a critical defect size $(\sqrt{\text { area }})$ in the range of $30 \mu \mathrm{m}$. In addition, a probabilistic approach based on the weakest link theory is proposed. The model describes a probabilistic Kitagawa-Takahashi diagram accounting for the size of both the highly stressed volume and the natural defect.

Keywords: high cycle fatigue; additive manufacturing; Ti-6Al-4V; titanium, porosity; size effect; powder bed fusion; Kitagawa-Takahashi diagram;
\end{abstract}




\section{Introduction}

In LPBF (Laser Powder Bed Fusion) components, there is a consensus that the presence of defects is the factor that limits the material's fatigue strength [1-4]. It is recognized by several authors that the variability in pore size, shape and location is pronounced, even under closely controlled manufacturing conditions [4-6]. In addition, the microstructure resulting from layer manufacturing may also show other heterogeneities such as in the grain size and shape as discussed in the literature review by Kok et al. [7].

The Ti-6Al-4V titanium alloy studied in this work is one of the most common alloys manufactured by LPBF with applications in many industries, in particular the aeronautic and the medical domains. The monotonic mechanical properties of the Ti-6Al-4V alloy processed by LPBF are close to those of its hot rolled counterpart [1-4]. Nevertheless, the presence of pores, typical of LPBF manufacturing, reduces the average fatigue strength and increases its dispersion [4-6]. From the literature, all fatigue specimens made of Ti-6Al-4V without a HIP (Hot Isostatic Pressure) treatment, encountered crack initiation from process related discontinuities, typically, gas pores or lack of fusion pores [5, 6, 8--10]. On the other hand, for HIP-LPBF-Ti-6Al-4V, the literature data agree that the material fatigue strength is closed to its hot rolled counterpart [6, 11, 13]. HIPping also efficiently reduces the scatter in the fatigue strength that characterizes LPBF-Ti-6Al4V [12, 13]. In HIP specimens, prior- $\beta$ grain boundaries and/or adjacent $\alpha$ colonies have been found to play a crucial role in fatigue crack initiation [14]. To the author's knowledge, the fatigue resistance of un-HIPped defect free LPBF-Ti-6Al-4V samples has yet to be characterized.

It is generally accepted that the fatigue strength of metals is sensitive to the tested volume. The so-called size effect was first studied in the 1960s by Pogoretskii who observed that fatigue strength decreased with an increase in specimen length [15]. The size effect is most often revealed when testing materials containing discontinuities like inclusions in laminated steels [16, 17] or pores in cast alloys [18, 19]. It has has also been observed in materials having for weakest link microstructural features such as Al 7050 alloys [20]. Because of the size effect, the experimentally determined fatigue strength can be influenced by the size and geometry of the specimens used. In

${ }^{*}$ Corresponding author: Etienne PESSARD

Email address: etienne.pessard@ensam. eu (Etienne PESSARD) 
the case of AM-materials the minimum and maximum pore sizes observed at the fatigue crack initiation site are limited by the tested volume. In the work by Hu et al. [21] on a LPBF-Ti-6Al-4V, the lack of fusion pore sizes observed at the initiation sites are comprised between 30 et $72 \mu \mathrm{m}$, even if 21 specimen were tested. This small range illustrates the difficulty in characterising the defect size sensitivity in fatigue using only one specimen geometry. The solution to this problem would therefore be to use very small specimens to obtain failure from small defects or even without a defect and to use very large specimens to characterize the sensitivity to the largest defects.

In order to simplify the experimental problems caused by using different specimens geometries, different numbers of hemispherical surface holes have been machined into the specimens to modify the size of the highly stressed volume. A similar strategy, has been successful used by Abroug et al. [20] on a 7050 aluminium alloy.

The goal of this work is to study the effect of the tested volume size on the fatigue strength at $2 \times 10^{6}$ cycles of LPBF-Ti-6Al-4V. Three specific objectives are treated: 1) to determine the fatigue strength sensitivity to the natural defect size, 2) to characterize the "defect-free" material fatigue strength for cracks initiating from micostructural features not classified as defects, 3) to characterize the size effect for "defect-free" samples and to compare the behaviour with the results gathered in 1).

In order to fulfil these objectives, a vast experimental fatigue campaign under push-pull loading conditions (load ratio of $\mathrm{R}=-1$ ) has been undertaken. In the first part of this paper, the manufacturing process used to obtained specimens with different highly stressed volumes is presented. The material, its microstructure and the pore population, characterized by optical microscopy, are then presented. In the second section, the fatigue strengths determined at $2 \times 10^{6}$ cycles for four specimen configurations with different Highly Stressed Volumes (noted HSV in this paper). Finally, a probabilistic approach that leads to a Kitagawa-Takahashi diagram [22] is proposed and discussed.

\section{Experimental methodology}

\subsection{Specimen manufacturing}

Cylindrical bars were manufactured using a SLM $280 \mathrm{HL}$ machine with a $278 \times 278 \times 325 \mathrm{~mm}^{3}$ chamber, with a regulated argon atmosphere containing less than $0.1 \%$ in volume of oxygen. The 


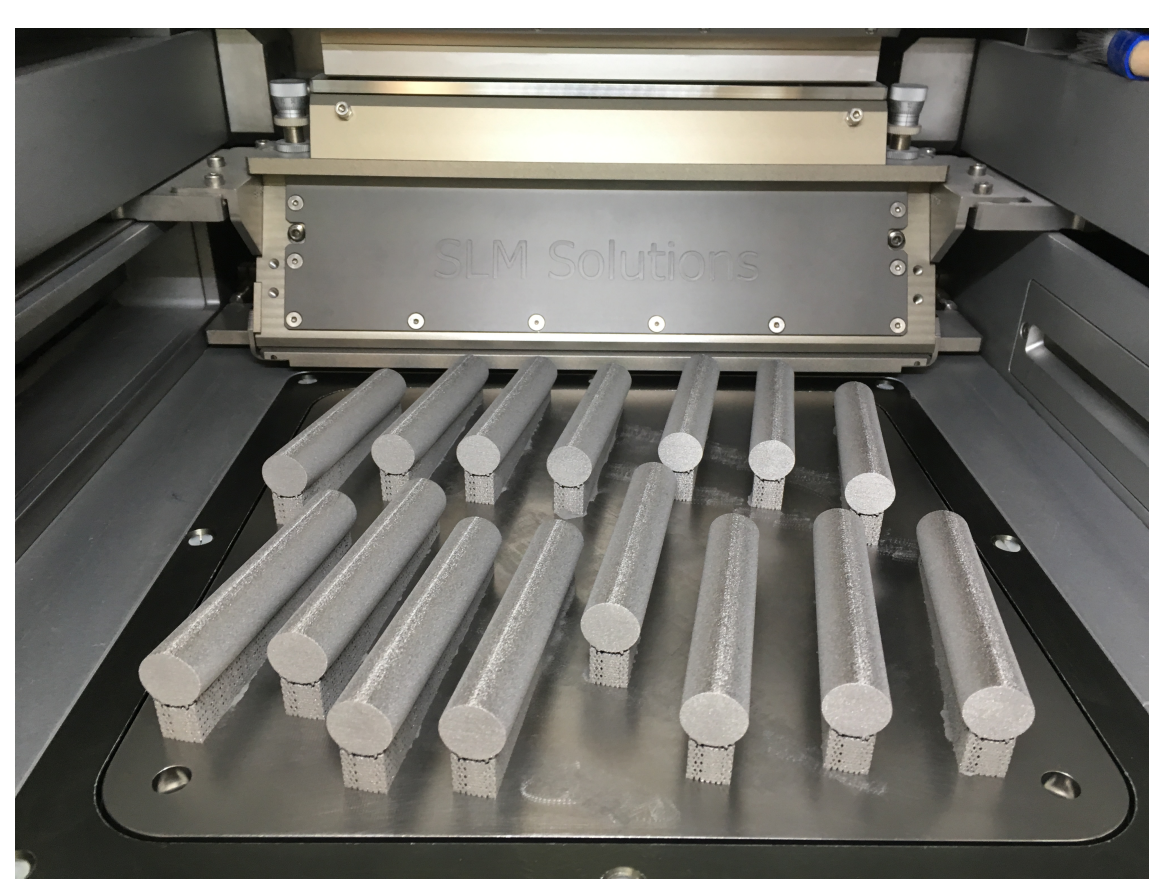

Fig. 1: Ti-6AL-4V fatigue sample in the SLM 280HL machine.

specimens were built in the horizontal direction to reduce the impact of the lack-of-fusion on fatigue and increase the probability of triggering crack initiation from a microstructural feature as shown in Fig.1, on a plateform preheated at $200^{\circ} \mathrm{C}$.

The powder layer thickness, set to $30 \mu \mathrm{m}$, was controlled by the vertical displacement of the building platform. A laser with a spot diameter of about $70 \mu \mathrm{m}$ traveled in a continuous scan mode at a scanning speed of $\mathrm{V}=775 \mathrm{~mm} / \mathrm{s}$. A cross hatching strategy was used where the scanning direction is switched by $67^{\circ}$ between successive layers. The hatch (distance between two laser tracks) was set to $100 \mu \mathrm{m}$ and the laser power to $175 \mathrm{~W}$.

All bars were removed from the build plate and then annealed at $850^{\circ} \mathrm{C}$ for 2 hours under vacuum and cooled down within the furnace to obtain an alpha + beta microstructure. Fatigue specimens with the dimensions given in Fig 2 were machined from the heat treated bars.

The reduced section of the specimens were manually polished with $\mathrm{SiC}$ abrasive paper to provide a mirror-like surface with a roughness of $\mathrm{Ra}<0.1 \mu \mathrm{m}$. Hemispherical artificial defects with a diameter of $600 \mu \mathrm{m}$ were then machined on the surface of some specimens by micro-drilling using a carbide tool. After drilling, the defects were scanned with a 3D BRUKER profilometer to 


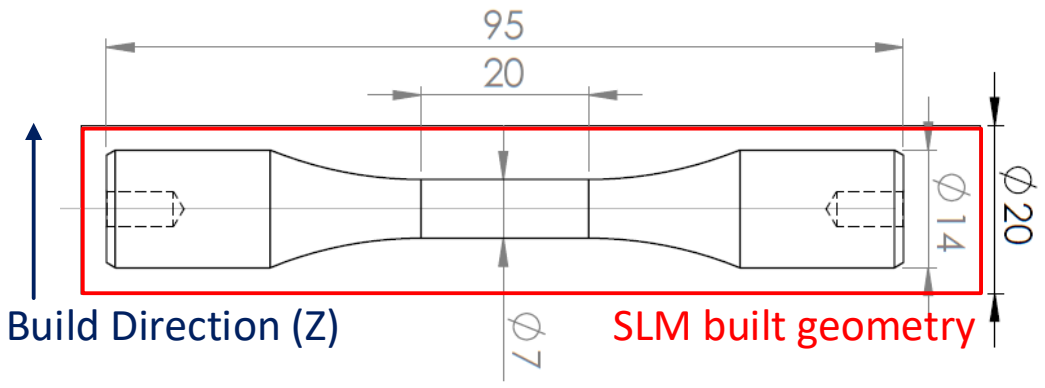

Fig. 2: Cylindrical fatigue sample dimensions with the as-built geometry, (dimensions are in mm).

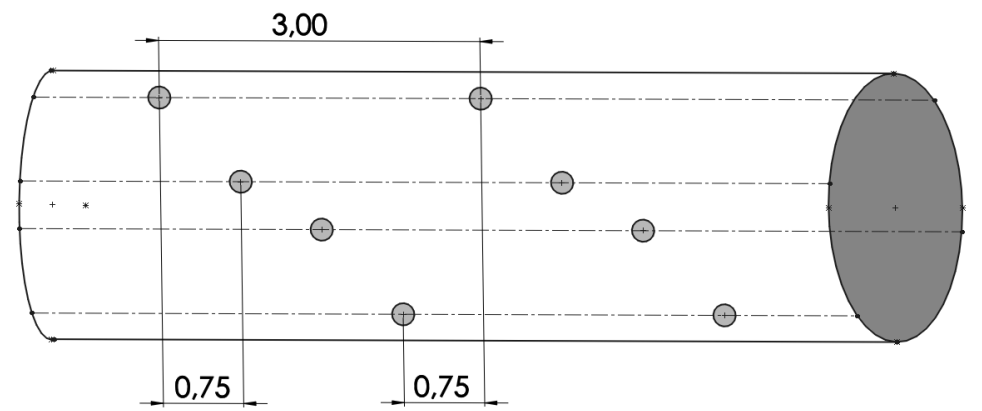

Fig. 3: Hemispherical holes surface spatial distribution on the specimenmerged (dimensions are in mm).

The notches have been distributed, in four lines of the specimen (situated at $0,45,90$ and $135^{\circ}$ ) around the specimen contour to facilitate micro drilling. The hole-position on the sample axis has been chosen to avoid interaction between defects. On a given line the distance between defects is equal to $3 \mathrm{~mm}$. The distance between 2 drilling planes is $0.75 \mathrm{~mm}$ to avoid positioning two defects in the same cross section.

A final heat treatment was carried out at $650^{\circ} \mathrm{C}$ for 4 hours under vacuum followed by ambient cooling to relax any potential residual stresses introduced by micro-drilling. A sample containing 32 artificial defect is shown in Fig 6 a).

\subsection{Material, microstructure and natural pores}

The Ti-6Al-4V alloy used in this study is grade 23 ELI dedicated to aeronautical applications. Its standradized chemical composition as per ASTM F3001-14 in weight fraction is given in Table 


\begin{tabular}{ccccccccc}
\hline Element & $\mathrm{Ti}$ & $\mathrm{Al}$ & $\mathrm{V}$ & $\mathrm{C}$ & $\mathrm{Fe}$ & $\mathrm{H}$ & $\mathrm{N}$ & $\mathrm{O}$ \\
\hline $\mathrm{wt} \%$ & Bal. & $5.5-6.0$ & $3.5-4.5$ & $\leq 0.08$ & $\leq 0.25$ & $\leq 0.012$ & $\leq 0.05$ & $\leq 0.13$ \\
\hline
\end{tabular}

Table 1: Standardized chemical compositions of the Ti-6Al-4V alloy as per ASTM F3001-14 [23].

The Ti-6Al-4V powder, obtained by inert gas atomization, was supplied by TLS (Technik GmbH\&Co Speziapulver-Germany). The particle size distribution was measured using a dynamic image analysis instrument "CAMSIZER XT" that provides the following results: D10=36 $\mu \mathrm{m}$, $\mathrm{D} 50=46 \mu \mathrm{m}, \mathrm{D} 90=53 \mu \mathrm{m}$. This indicates that $10 \%$ in volume of the powder particles have a diameter smaller than $36 \mu \mathrm{m}$ and $10 \%$ larger than $53 \mu \mathrm{m}$.

To characterize the microstructure and the pore size distribution, eleven cross-sections were extracted from one drilled and heat treated specimen and prepared for metallographic observations. The microstructure of the polished and etched samples was characterised using an optical microscope. A columnar microstructure showing grains elongated parralell to the building direction was observed as shown in Fig. 4 a). Typical lack of fusion and gas pores were also observed as shown on Fig. 4 c) and 4 d) respectively.

The pore size distribution, shown in Fig 5 was characterized using the square root of the pore area $(\sqrt{\text { area }})$. Pores with a $\sqrt{\text { area }}$ greater than $7 \mu \mathrm{m}$ were counted on the $2 \mathrm{D}$ images observed by an optical microscope. A total of 2109 pores were characterized on a surface covering $425 \mathrm{~mm}^{2}$ which resulted in an average defect density of 5 pores $/ \mathrm{mm}^{2}$.

\subsection{Fatigue testing}

In order to characterize the scale effect, specimens containing different number of surface holes (1, 8 and 32) were tested (see Table 2). In addition, 4 specimens without hemispherical surface holes, were also tested to characterize the fatigue strength for large highly stressed volumes.

The fatigue tests were carried out on a dynamic drive Rumul Testronic machine. An axial cyclic stress was applied normal to the building direction with a load ratio of $R=F_{\min } / F_{\max }=-1$. The test frequency was approximately $105 \mathrm{~Hz}$. The step technique proposed by Maxwell and Nicholas [24] developed to rapidly characterize the fatigue strength at a given number of cycles 

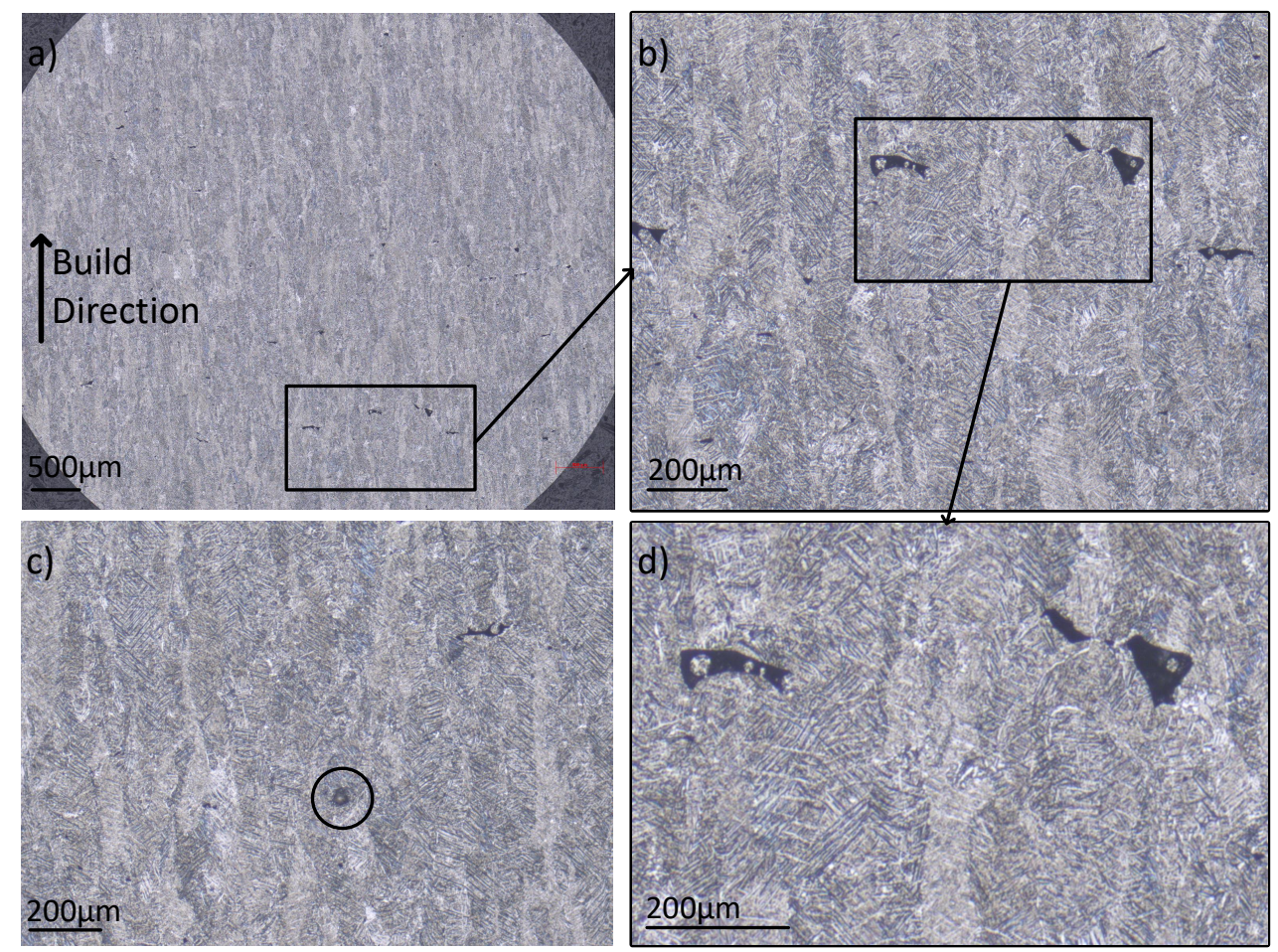

$\mathrm{m}$

Fig. 4: Optical microscopy microstructure observation at different magnification showing a) the columnar microstructure, c) gas pore, b) and d) typical lack of fusion defects.

was used. The initial nominal stress amplitude was chosen to be slightly below the fatigue strength at $2 \times 10^{6}$ cycles. If the sample did not fail after $2 \times 10^{6}$ cycles, the stress amplitude was increased by $20 \mathrm{MPa}$ until failure occurred before reaching $2 \times 10^{6}$ cycles. The test was stopped when a 1 $\mathrm{Hz}$ drop in frequency was detected, which corresponds to a crack length of several millimetres as shown in Fig.6 b).

In order to take into account the potential damage caused by the preliminary fatigue cycles, the fatigue strength at $2 \times 10^{6}$ cycles was adjusted using equation 1 proposed by Nicholas et al. [24].

$$
\sigma_{f, a}=\left(\sigma_{a, n}-\sigma_{a, n-1}\right) * \frac{N_{f}}{2 * 10^{6}}+\sigma_{a, n-1}
$$

where $\sigma_{f, a}$ is the adjusted fatigue strength, $\sigma_{a, n}$ is the stress amplitude at wich failure occurred, $\sigma_{a, n-1}$ is the stress amplitude of the previous block load and $N_{f}$ the number of cycles at failure for $\sigma_{a, n}$. This method assumes that the damage induced by the previous loading blocks (n-i with $\mathrm{i}>1$ ) 


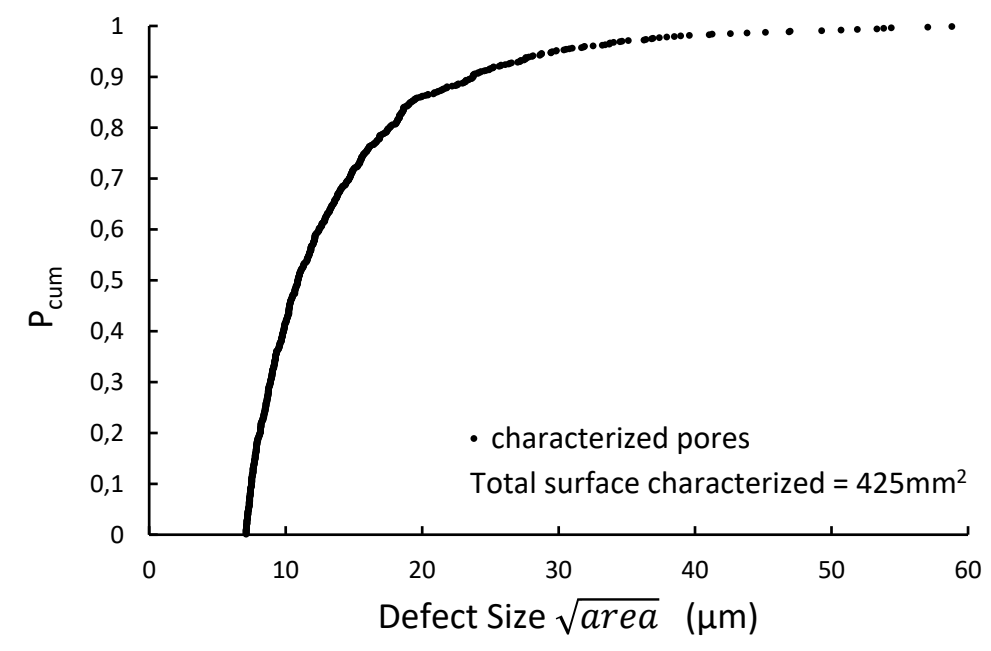

Fig. 5: Cumulative size distribution of the defects for $\sqrt{\text { area }} \geq 7 \mu \mathrm{m}$

is negligible. This assumption is applied to all the results presented in this paper as no drop in frequency was observed for the load blocks $n-i$ where $i>1$. Unless indicated, all samples survived at least one full block of $2 \times 10^{6}$ cycles.

A fatigue strength correction was also made for specimens with a failure plane located outside the reduced section of the specimen. The corrected nominal fatigue strength was given by the axial force divided by cross-sectional area of the failure plane, which results in slightly lower stress amplitudes than the nominal stress (generally 0.92 to 1.0 times the nominal stress amplitude calculated in the gauge section).

\section{Experimental results and pore effect analysis}

\subsection{Fatigue results}

The results of the fatigue tests are reported in Table 2 and Fig.7. When comparing the average nominal stress amplitudes that caused the failure of specimens without artificial defects (i.e. specimens D0-i) to the specimens with artificial defects (i.e. specimens D1-i, D8-i, D32-i), two observations stand out. The specimens without artificial defects did not resist significantly higher 


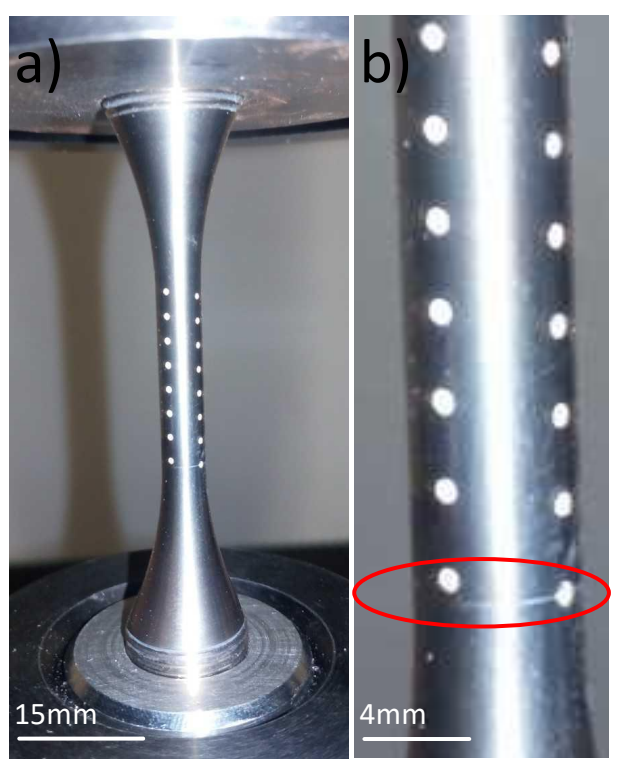

Fig. 6: a) Picture of the specimen containing 32 artificial defects, b) at higher magnification a crack that initiated from an artificial defect is surrounded in red.

nominal stress amplitudes than the specimens with one artificial defect. Some specimens (D1-7 and D8-6) with an artificial defect failed due to a nominal stress amplitude that was greater than the maximum nominal strength of smooth samples (D0-1, D0-2, and D0-3). This is counter intuitive given that the presence of an artificial defect locally raises the stress by a factor of 2 , as will be shown in section 3.3. Nevertheless, as the number of artificial defects increases, the average nominal stress at failure converges toward a lower value. This trend will be explained by studying the synergy between the artificial defects and natural defects.

\subsection{Fatigue damage mechanisms}

The fractographic observation of all failed specimens revealed the presence of two categories of features at the fatigue crack initiation sites: 1) process related discontinuities (e.g. lack of fusion pores) and 2) microstructural features. This is reported in the $8^{\text {th }}$ column of Table 2 .

As part of the 18 specimens for which a crack initiated at a natural defect, 17 were caused by a lack of fusion pore (LoF) located at the surface or less than $20 \mu \mathrm{m}$ from the surface. As illustrated in Fig.8, LoF defects have been observed at the crack initiation sites of 13 specimens with artificial defects and 4 specimens without artificial defects. 
Table 2: Fatigue test results fo a target fatigue life of $2 \times 10^{6}$ cycles

\begin{tabular}{|c|c|c|c|c|c|c|c|c|}
\hline Specimen & $\begin{array}{l}\text { Defects } \\
\text { Number }\end{array}$ & $\begin{array}{l}\text { Nominal Stress A } \\
\text { at Failure (MPa) }\end{array}$ & $\begin{array}{l}\text { plitude } \\
\text { Average (MPa) }\end{array}$ & $\begin{array}{l}\text { Step } \\
\text { Number }\end{array}$ & $\begin{array}{l}N_{f} \\
\left(10^{6} \text { cycles }\right)\end{array}$ & $\begin{array}{l}\sigma_{f, a, \text { local }} \\
(\mathrm{MPa})\end{array}$ & Initiation Type & $\begin{array}{l}\sqrt{\text { area }} \\
(\mu \mathrm{m})\end{array}$ \\
\hline D0-1 & 0 & 210 & \multirow{4}{*}{275} & 1 & 0.92 & $199^{2}$ & natural defect & 116 \\
\hline D0-2 & 0 & 250 & & 1 & 0.20 & $232^{2}$ & natural defect & 150 \\
\hline D0-3 & 0 & 270 & & 5 & 1.73 & $248^{1}$ & natural defect & 73 \\
\hline D0-4 & 0 & 370 & & 10 & 1.63 & $341^{1}$ & natural defect & 26 \\
\hline D1-1 & 1 & 170 & \multirow{7}{*}{270} & 2 & 0.72 & $147^{1}$ & natural defect & 169 \\
\hline D1-2 & 1 & 250 & & 3 & 0.50 & 357 & AD-natural defect & 35 \\
\hline D1-3 & 1 & 270 & & 4 & 1.07 & $249^{1}$ & natural defect & 74 \\
\hline D1-4 & 1 & 270 & & 4 & 0.22 & 252 & natural defect & 55 \\
\hline D1-5 & 1 & 290 & & 9 & 0.57 & 551 & AD-microstructure & / \\
\hline D1-6 & 1 & 290 & & 5 & 0.69 & 554 & $\mathrm{AD}$-microstructure & / \\
\hline D1-7 & 1 & 350 & & 11 & 0.17 & 663 & AD-microstructure & / \\
\hline D8-1 & 8 & 210 & \multirow{6}{*}{257} & 4 & 0.79 & 290 & AD-natural defect & 41 \\
\hline D8-2 & 8 & 230 & & 3 & 0.2 & 307 & AD-natural defect & 31 \\
\hline D8-3 & 8 & 250 & & 4 & 0.31 & 384 & AD-natural defect & 25 \\
\hline D8-4 & 8 & 250 & & 4 & 0.19 & 264 & AD-natural defect & 54 \\
\hline D8-5 & 8 & 270 & & 7 & 1.15 & 522 & AD-microstructure & / \\
\hline D8-6 & 8 & 330 & & 10 & 0.06 & 621 & $\mathrm{AD}$-microstructure & l \\
\hline D32-1 & 32 & 130 & \multirow{7}{*}{201} & 1 & 1.05 & $127^{2}$ & AD-natural defect & 225 \\
\hline D32-2 & 32 & 150 & & 1 & 0.56 & $161^{2}$ & AD-natural defect & 127 \\
\hline D32-3 & 32 & 230 & & 6 & 0.36 & 389 & AD-natural defect & 13 \\
\hline D32-4 & 32 & 250 & & 7 & 0.33 & 383 & AD-natural defect & 19 \\
\hline D32-5 & 32 & 270 & & 8 & 0.76 & 310 & AD-natural defect & 81 \\
\hline D32-6 & 32 & 190 & & 4 & 0.10 & 342 & AD-microstructure & / \\
\hline D32-7 & 32 & 190 & & 3 & 0.44 & 349 & AD-microstructure & / \\
\hline D32-8 & 32 & 110 & 110 & 1 & 0.51 & $98^{2}$ & Layer delamination & / \\
\hline \multicolumn{4}{|c|}{${ }^{1}$ : Corrected stress, fracture plane outside the gauge length. } & \multicolumn{5}{|c|}{ natural defect initiation type $: \sigma_{f, a, l o c a l}=\sigma_{f, a, \text { nominal }}$} \\
\hline \multicolumn{4}{|c|}{ 2: Fracture during the first step. } & \multicolumn{5}{|c|}{ AD-microstructure initiation type $: \sigma_{f, a, \text { local }}=K_{t} \sigma_{f, a, \text { nominal }}$} \\
\hline \multicolumn{4}{|c|}{ AD: crack initiation from an artificial defect. } & \multicolumn{5}{|c|}{ AD-natural defect initiation type $: \sigma_{f, a, l o c a l}=K_{t, d^{*}} \sigma_{f, a, \text { nominal }}$} \\
\hline
\end{tabular}

All process related defects, observed at the crack initiation sites were measured and reported in terms of the Murakami parameter $\sqrt{\text { area }}$ (square root of the defect area projected onto a plane perpendicular to the applied stress) [25]. These values are reported in the last column of Table 2.

Sample D32-8 showed a particularly low fatigue strength, as its failure occurred during the first loading step at a stress amplitude of $110 \mathrm{MPa}$. As illustrated in Fig. 9, large linear LoF pore can be seen at the surface of the hemispherical artificial defect. These linear defect act as pre-existing 


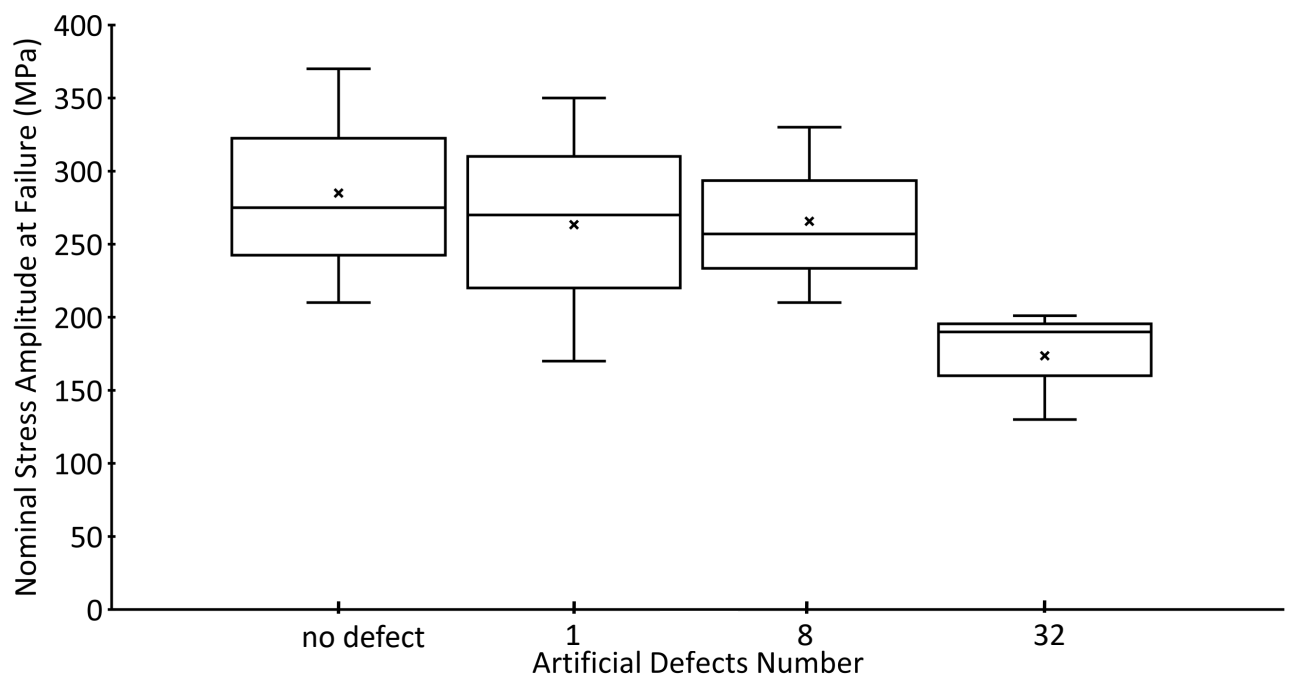

Fig. 7: Average and range of the Nominal Stress Amplitude at Failure in function of the artificial defects number.

cracks and have a detrimental effect on the fatigue strength. An observation of the overall fracture surface shows that the LoF pores are aligned between melt pools. This kind of failure surface, not much discussed in the literature, is characteristic of delamination which is occasionally reported in L-PBF materials. Andreau et al. [26] observed delamination on a 316L L-PBF stainless steel in samples where pores covered more than $10 \%$ of the cross section. Similarly, the failure surface of the delaminated sample presented in Fig.9, also showed a high surface fraction of pores (in black on the failure surface).

For 7 out of 25 specimens, no pores were observed at the crack initiation sites as shown in Fig. 10. In these cases, it was assumed that cracks initiated from the microstructure, most probably from $\alpha$ laths or colonies as report in the literature [14, 27, 28] for similar alloys.

\subsection{Impact of artifical defects on fatigue strength}

Finite element simulation of the elastic stresses around an artificial defect were conducted using the following material elastic constants: $\mathrm{E}=110 \mathrm{GPa}$ and $v=0.34$. The results of the simulation, shown in Fig 11, confirm that the stress concentration factor $\left(K_{t}\right)$ characterizing an artificial defect is equal to 2 . The fatigue notch factor $K_{f}$ is hypothetically considered equal to the stress concentration factor, as experimentally shown by Lanning et al. [29] for wrought Ti-6Al-4V 

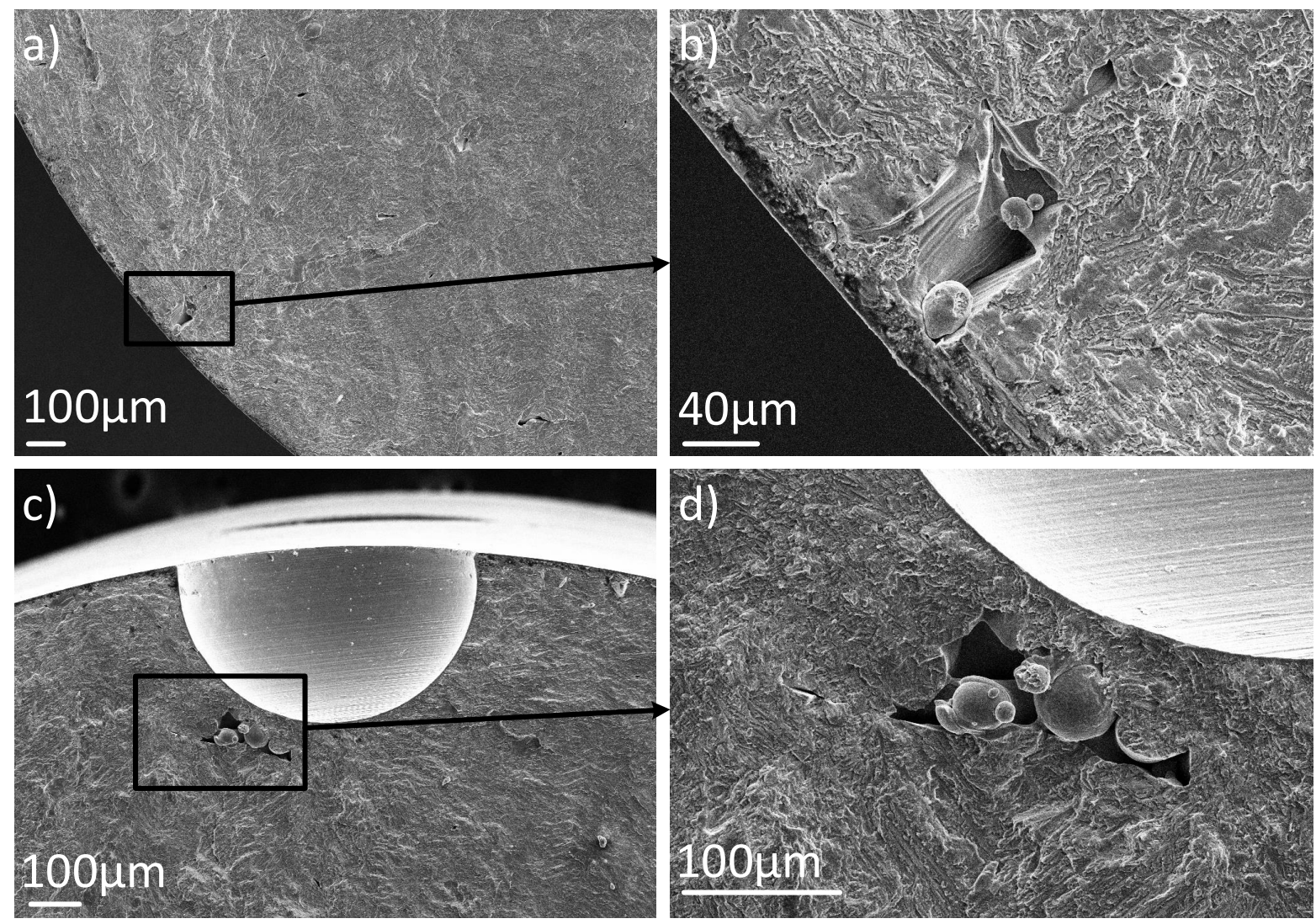

Fig. 8: Fracture surface of samples a-b) D1-3 where the lack of fusion that caused crack initiation is not in the vicinity of an artificial defect and c-d) D32-5 showing crack initiation from lack of fusion pore, located at the root of an artificial defect.

notched cylindrical specimens $\left(K_{t}=2.72\right)$ under push-pull loads. Therefore, it is assumed that the local stress at the root of the artificial defect can be estimated by:

$$
\sigma_{f, a, \text { local }}=K_{t} \sigma_{a, \text { nominal }}
$$

On the plane of maximal normal stress, the $K_{t}$ remains quasi constant around the defect with a decrease of only $4.2 \%$ when comparing stress value in the depth and at the surface. Equation 2 was used to calculated $\sigma_{f, a, l o c a l}$ reported in Table 2 for all of the samples identified as "ADmicrostructure".

For specimen with a natural defects found in the vicinity of an artificial defect (AD-natural 

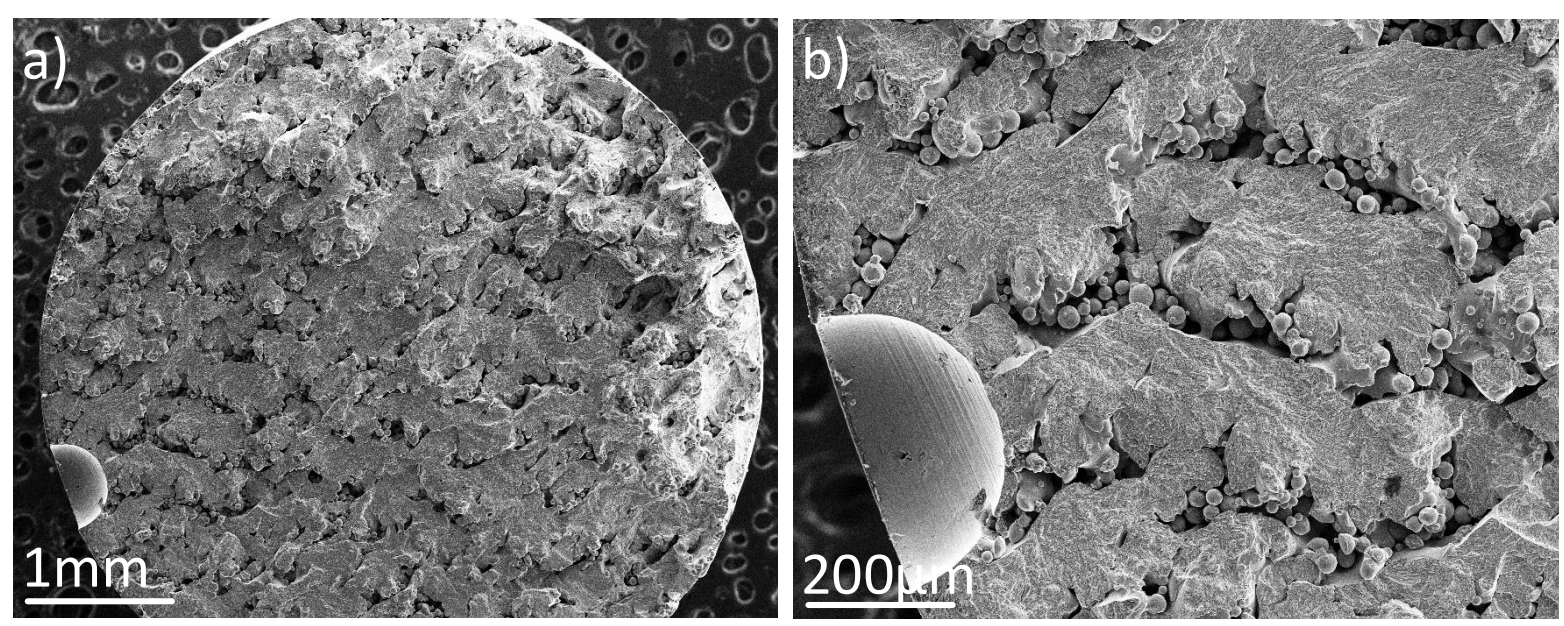

Fig. 9: Fracture surface of sample D32-8 showing a layer delamination.
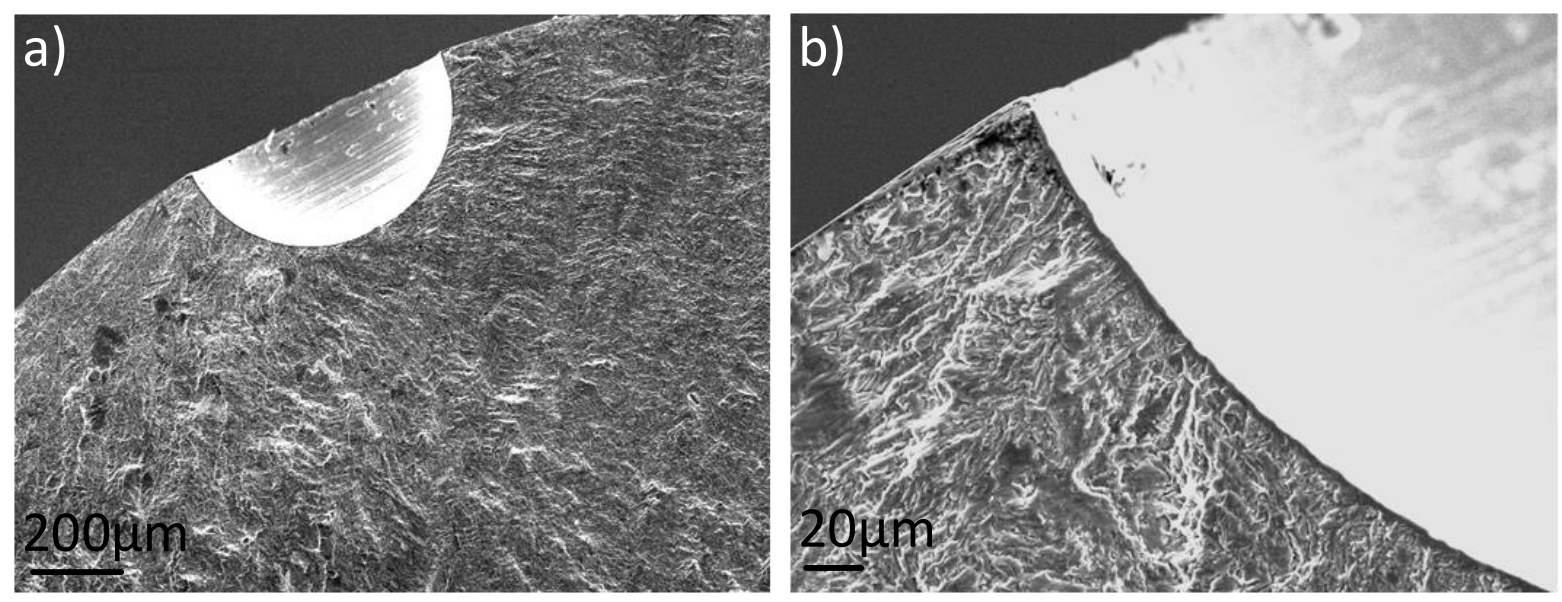

Fig. 10: Fracture surface of sample D32-6 showing initiation from microstructure without any pore.

defect), the local stress at the tip of the natural defect is reported. The results of finite element analysis was used to quantify the stress concentration factor $\left(K_{t, d^{*}}\right)$ for specific positions underneath the artificial defect, $d^{*}$, as shown in Fig.11 and Fig.12. The natural defect is therefore not explicitly modelled but the stress gradient in the vincity of the hemispherical hole is take into account.

For each specimen, the local stress was quantified at the tip of the initiation defect using equa- 
tion 3 .

$$
\sigma_{f, a, l o c a l}=K_{t, d^{*}} \sigma_{f, a, \text { nominal }}
$$

a)

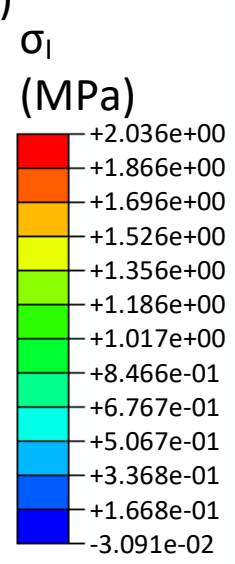

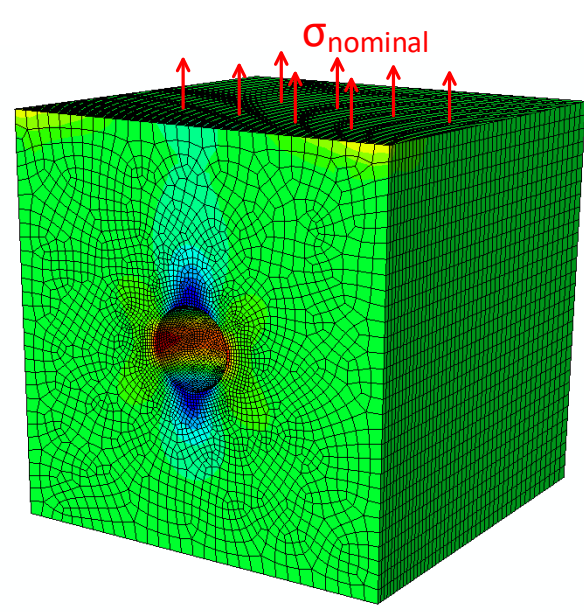

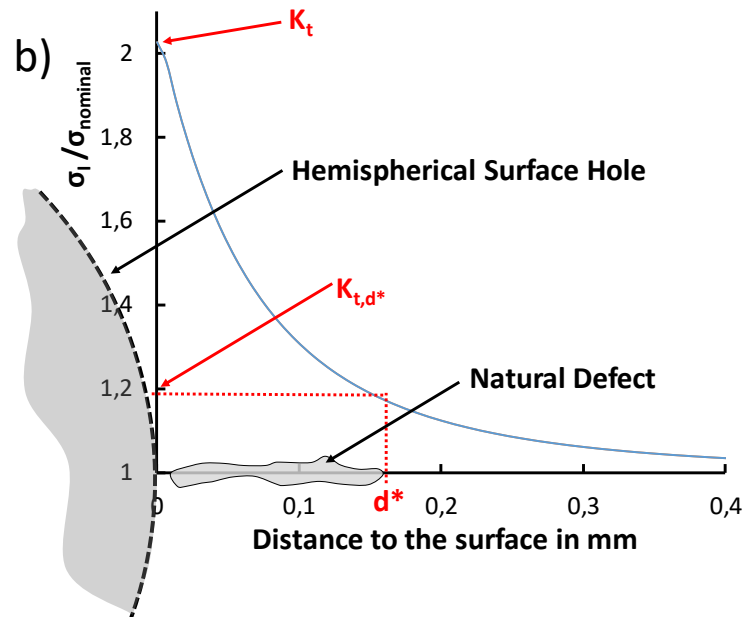

Fig. 11: a) Finite Element simulation in elasticity of a elementary volume containing a $600 \mu \mathrm{m}$ diameter hemispherical defect, the arbitrary intensity stress load in tension is $1 \mathrm{MPa}$, maximum principal stress $\sigma_{I}$ field are given by the color code, b) stress distribution in depth from the free surface of the hemispherical surface hole.

The local fatigue strength $\sigma_{f, a, \text { local }}$ is reported in the $7^{\text {th }}$ column of Table 2 . These values are calculated at the tip of the artificial defect for all specimens with the crack initiation type "ADmicrostructure" and at the tip of the natural defect for the specimens with the "AD-natural defect" initiation type.

In Fig.13, the local fatigue strength of all sample are plotted as a function of square root area $\sqrt{\text { area }}$ of the defect observed at the crack initiation site. This diagram is presented on a log-log scale in order to appreciate the power law relationship that typically describes the influence of large defects on the fatigue strength as proposed by Kitagawa-Takahashi in 1976 [22]. For crack initiation at microstructural features (i.e. defect-free), the fatigue strength is plotted at $\sqrt{\text { area }}=1 \mu \mathrm{m}$. In presence of natural defects, the data obtained from specimen with and without hemispherical surface hole presented on Fig 13 are not significantly different. This indicates that the proposed tress correction for presence of natural defect in the vicinity of a hole is fair.

Fig. 13 demonstrates the detrimental effect of defects on the fatigue strength. For all specimens containing a natural defect with $\sqrt{\text { area }}>19 \mu \mathrm{m}$, the fatigue strength can be estimated by a power 
law relationship of the defect size $(\sqrt{\text { area }})$ with an exponent of $-0.5\left(\sigma_{f, a, \text { local }}=B(\sqrt{\text { area }})^{0.5}\right)$. Such a power law relationship well describes the linear elastic fracture mechanics principles where the fatigue strength can be expressed by:

$$
\sigma_{a}=\frac{\Delta K_{t h}}{F \sqrt{\pi \sqrt{\text { area }}}}
$$

where $\mathrm{F}$ is a dimensionless factor which equal to 0.65 for an hemispherical surface defected considered as an pre-existing crack in a body of infinite size. For load ratios smaller or equal to $0(\mathrm{R} \leq 0)$ it is generally recognized that the positive portion of the load is the sole contributor to long crack propagation in metals, as proposed in ASTM E647 [30]. Therefore, in equation 4, the expression of delta $\Delta K=K_{a m p}=K_{\max }$ has been used and $\Delta \sigma$ can be replaced by $\sigma_{\max }$.

Fig. 13 can also be use to estimate the material's resistance to fatigue in the absence of a crack initiating discontinuity. The results presented by open circles were obtained for specimens with no observable pores in the vicinity of the crack initiation region. These results (AD-microstructure) ranged from 342 to $663 \mathrm{MPa}$. It can also be observed that the presence of defects smaller than $30 \mu \mathrm{m}$ at the crack initiation sites resulted in fatigue strengths of $341,383,384$ and $389 \mathrm{MPa}$, which is the same range as the defect-free samples. It suggests that the critical defect size, which is detrimental to the fatigue strength of the studied LPBF-Ti-6Al-4V is approximately $\sqrt{\text { area }}=30$ $\mu \mathrm{m}$.

In the next section an attempt to correlate the dispersion in the measured fatigue strength to the size of the Highly Stressed Volume (HSV) is presented. In addition the scatter in $\Delta K_{t h}$ will also be accounted for in a probabilistic Kitagawa-Takahashi diagram.

\section{Probabilistic Kitagawa-Takahashi diagram}

\subsection{Analysis of the volume effect}

To quantify the size of the HSV the approach proposed by Sonsino et al. [31] is used. These authors proposed that fatigue damage on component experiencing a stress gradient occurs essentially in the HSV. The authors defined the HSV to be the volume within which the Von-Mises stress amplitude is greater than $90 \%$ of the maximum stress amplitude in the component. Here, 

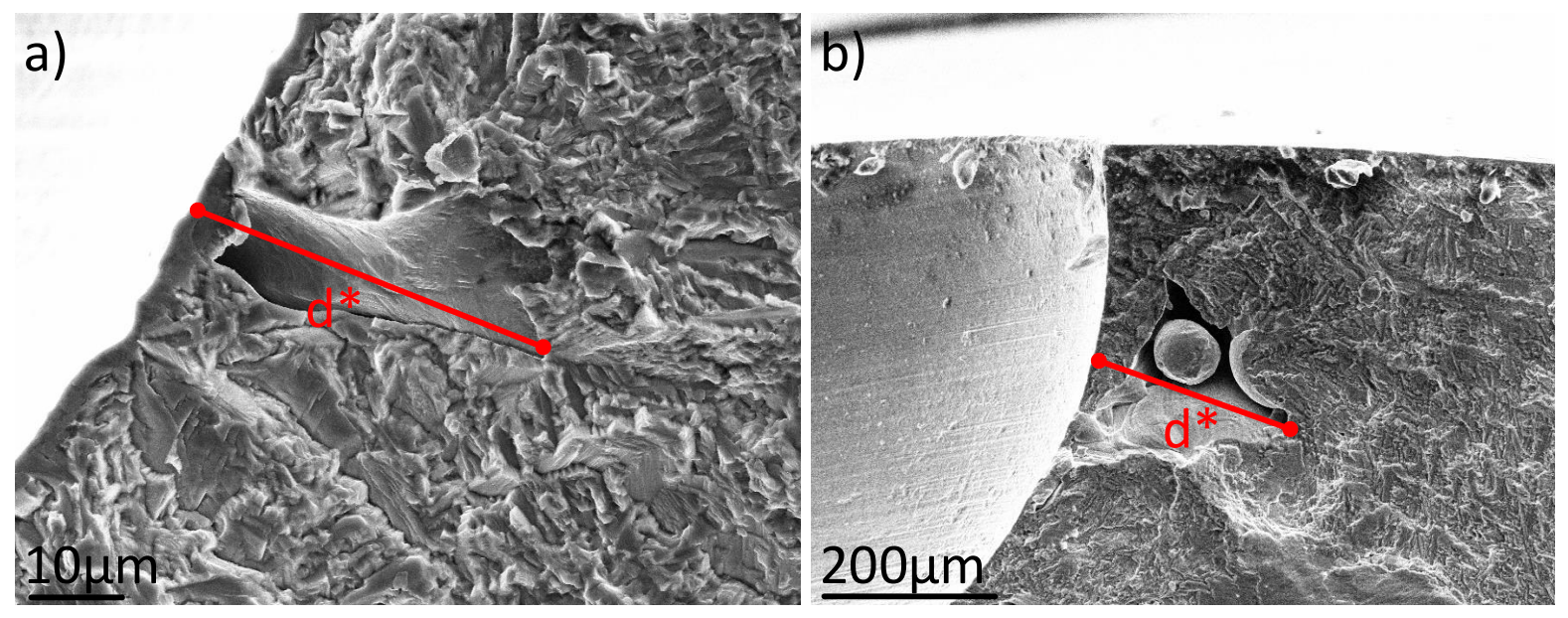

Fig. 12: Fracture surface of samples a) D32-4 and b) D32-2 illustrates the distances $\mathrm{d}^{*}$.

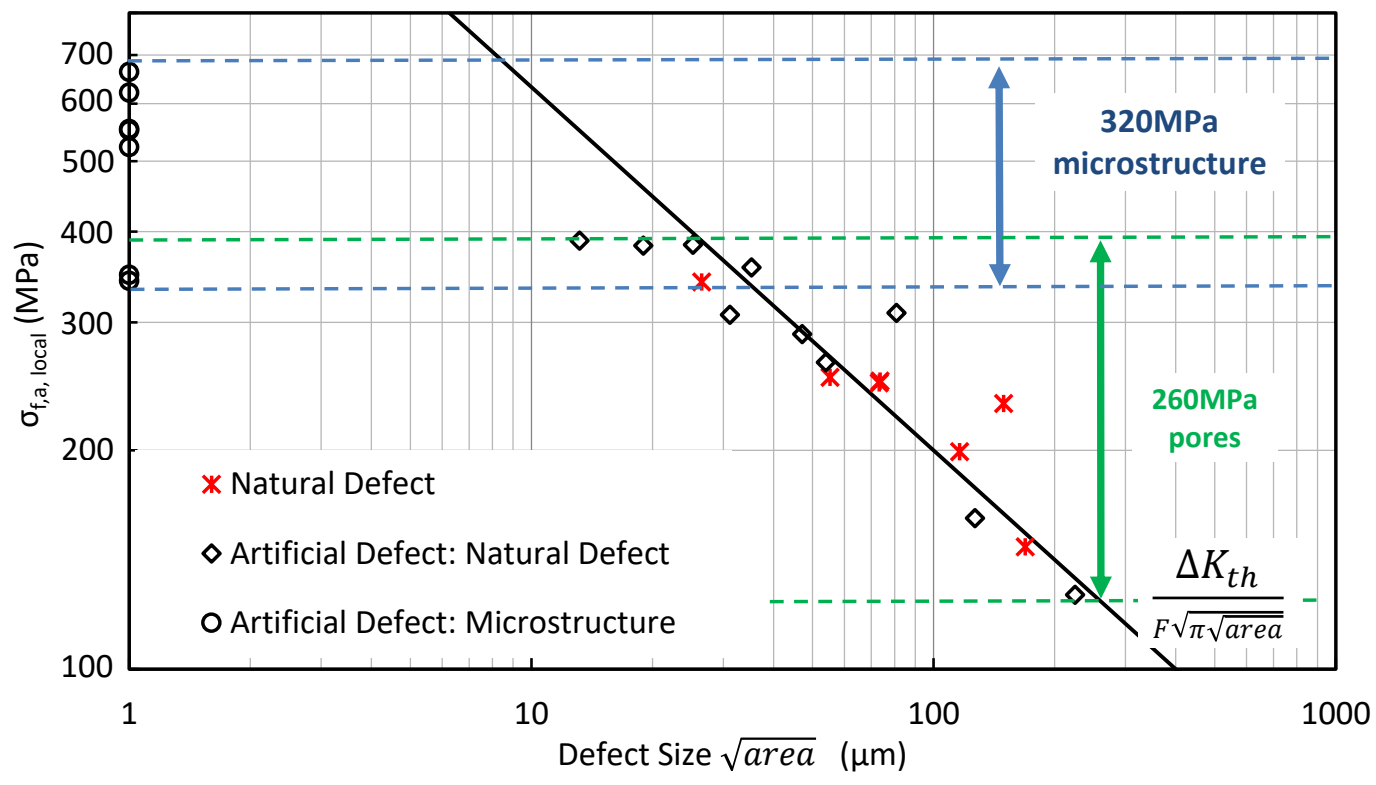

Fig. 13: Kitagawa-Takahashi diagram of all the samples using the local fatigue strength $\sigma_{f, a, l o c a l}$ for different fatigue initiation types. 
this principle is used to quantified the HSV in samples containing a stress gradient caused by the presence of the artificial defects. For the specimens described in this paper, V90\% equals 2.15, 17.2 and $68.9 \times 10^{-3} \mathrm{~mm}^{3}$ respectively for samples containing 1,8 and 32 hemispherical holes.

For specimen without artificial defect, the HSV (V90\%) is theoretically the volume of the reduced section, which equals $770 \mathrm{~mm}^{3}$. Nevertheless, experiments performed by Andreau et al. [26] on a $316 \mathrm{~L}$ stainless steel showed that cracks initiate at the surface even in the presence of internal defects that are 4 to 10 times larger than the surface defects. Based on this observation, it is proposed that fatigue damage mainly occurs within a surface layer or skin with a thickness of $20 \mu \mathrm{m}$, leading to a V90\% of $4.4 \mathrm{~mm}^{3}$. This thickness has been chosen to be equal to the $\alpha$ colony size, which is known to play a crucial role in crack initiation [14, 32]. Neikter et al. [33] proposed a typical colony size of $20 \mu \mathrm{m}$ in their extensive characterization work on LPBF-Ti-6Al-4V.

In Fig. 14, the evolution of the local fatigue strength $\sigma_{f, a, l o c a l}$ as a function of the highly stressed volume is presented for all specimens. For specimens with crack initiation at a pore $(\diamond)$, the fatigue strength is decreasing with the HSV. This can be explained by an increasing probability of encountering a large pore within larger HSV. The pore size reported in Table 3 is in agreement with this statement. This size effect has been reported by several authors who account for it using extreme values defect distribution [4, 34, 35].

For specimen with no observable defects at the crack initiation site (o), the average fatigue strength is even more sensitive to the HSV size. This size effect can be explain by microstructural heterogeneities. A larger HSV increases the probability of having a large colony of alpha laths favourably oriented for slip. For the smallest HSV, the fatigue strength reached values as high as $663 \mathrm{MPa}$ for specimen D1-7. These results illustrate that the local fatigue strength of the LPBF material can be very high, even higher than those usually obtained for a conventional specimen geometry with a HIP treatment (HIP-LPBF-Ti-6Al-4V - around $510 \mathrm{MPa}[13]$ ) and closed to those of hot rolled Ti-6Al-4V material (around $675 \mathrm{MPa}[13]$ )

\subsection{A probabilistic approach to model the volume effect}

In this section, a probabilistic Kitagawa-Takahashi diagram that accounts for the effect of the HSV on the fatigue strength and the experimental dispersion, measured in terms of $\Delta K_{t h}$ is pro- 


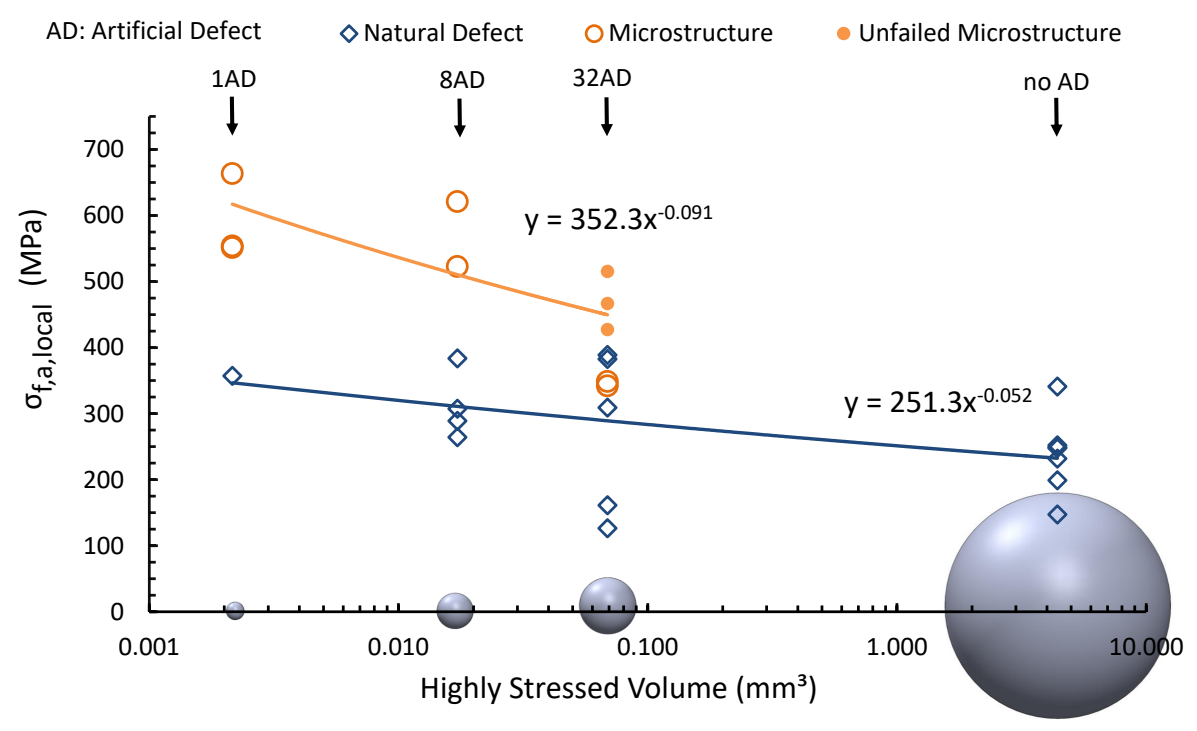

Fig. 14: Evolution of the local fatigue strength in function of the size of HSV. Results are presented using distinct symbols for failures that initiated at a natural defect (diamonds) and microstructure (circles). For all specimens, when a crack initiated from a natural defect at a smooth surface (not in an artificial defect), the result is reported in the category of the large HSV $\left(4,4 \mathrm{~mm}^{3}\right)$. The size of spheres is proportionate to the size of the tested HSV.

Table 3: Average pore size observed at crack initiation sites and percentage of failure without pore for the differents HSV tested

\begin{tabular}{ccccc}
\hline Number of Artificial Defect & 1 & 8 & 32 & 0 \\
\hline HSV $\left(10^{-2} \mathrm{~mm}^{3}\right)$ & 0.215 & 1.72 & 6.89 & 440 \\
\hline average pore size $(\mu \mathrm{m})$ & 35 & 39 & 92 & 95 \\
\hline failure without pores $(\%)$ & 42 & 33 & 25 & 0 \\
\hline
\end{tabular}

posed.

\subsubsection{Failure probability for defect free fatigue crack initiation}

To model the effect of the HSV on the fatigue strength when the microstructure controls the fatigue strength, a crack initiation threshold is defined at the mesoscopic scale (at the grain scale or the alpha colony scale) using a Weibull distribution. In the following, for convenience, the maximum principal stress criterion ( $\sigma_{a}$ for an axial load) is chosen, but other more complex thresholds could be used (i.e. equivalent stress, strain, energy, etc.). Hence, the condition for crack initiation 
is defined by:

$$
\sigma_{a} \geqslant \sigma_{t h}
$$

resulting in: 7 and 8 . $V_{\Omega}$.

$$
f_{01}\left(\sigma_{t h}\right)=\frac{m_{1}}{\sigma_{t h 0}}\left(\frac{\sigma_{t h}}{\sigma_{t h 0}}\right)^{m_{1}-1} \exp -\left(\frac{\sigma_{t h}}{\sigma_{t h 0}}\right)^{m_{1}}
$$

where $\sigma_{t h 0}$ is the scale parameter and $m_{1}$ is the shape parameter (or the Weibull exponent) used to reflect the scatter associated with the local intrinsic fatigue strength within the microstructure. Such a distribution can represent, for example, the effect of colony orientation on the initiation of a fatigue crack. The probability of triggering crack initiation can be expressed as the probability of having the applied mesoscopic stress amplitude reaching the local fatigue strength as in equations

$$
\begin{gathered}
P_{F_{01}}=\left(\sigma_{t h}<\sigma_{a}\right)=\int_{0}^{\sigma_{e q}} f_{01}\left(\sigma_{t h}\right) d \sigma_{a} \\
P_{F_{01}}=1-\exp \left[-\left(\frac{\sigma_{a}}{\sigma_{t h 0}}\right)^{m_{1}}\right]
\end{gathered}
$$

In order to account for the size of the HSV in the probability function, the weakest link theory proposed by Freudenthal [38] is used. In this framework, the probability of survival $\left(1-P_{F_{1}}\right)$ is defined as the product of the survival probabilities of each elementary volume $V_{0}$ in the volume

$$
1-P_{F_{1}}=\prod_{V_{\Omega}}\left(1-P_{F_{01}}(M)\right)
$$

$$
P_{F_{1}}=1-\exp \left[-\frac{1}{V_{0}} \int_{V_{\Omega}}\left(\frac{\sigma_{a}}{\sigma_{t h 0}}\right)^{m_{1}} d V\right]
$$


Within the experimental campaign presented in Table 3, four sample types with a specific volume sizes, $V_{\Omega}$, were tested. The failure probability of each sample type is described by equation 11

$$
P_{F_{1}}=1-\exp \left[-\frac{V_{\Omega}}{V_{0}}\left(\frac{\sigma_{a}}{\sigma_{t h 0}}\right)^{m_{1}}\right]
$$

From Eq. 11, the relation between the fatigue strengths noted $\sigma_{a, 1}$ and $\sigma_{a, 2}$ of two different loading volume sizes $V_{\Omega 1}$ and $V_{\Omega 2}$ can be written as:

$$
\frac{\sigma_{a, 2}}{\sigma_{a, 1}}=\left(\frac{V_{\Omega 1}}{V_{\Omega 2}}\right)^{1 / m_{1}}
$$

The parameter $m_{1}$ can therefore be obtained experimentally by fitting a power equation to the fatigue strength results as a function of the tested volume $V_{\Omega}$ as illustrated in Fig.14. This leads to a $m_{1}$ value of 10.98 for a failure probability of 0.5 .

Then, knowing $m_{1}$ and the average fatigue strength for an HSV, the gamma function is used to calculate the Weibull scale factor (see Eq, 13.

$$
\sigma_{t h 0}=\frac{\sigma_{a}}{\Gamma\left(1+1 / m_{1}\right)}
$$

where $\Gamma(t)=\int_{0}^{\infty} x^{t-1} e^{-x}$ is the gamma function [39]. Assuming $V_{0}$ is equal to the volume of a cube with a side length of $20 \mu \mathrm{m}$ can be used to model a $\alpha$ colony, this lead to a Weibull scale factor of the theoretical local intrinsic fatigue strength $\sigma_{t h}$ of $1.73 \times 10^{5} \mathrm{MPa}$.

\subsubsection{Failure probability due to propagation from natural defects}

As shown previously, the evolution of the fatigue strength as a function of the natural defect size (Fig. 13 ) is well described using the LEFM approach defined by Eq. 4 when $\sqrt{\text { area }}>30 \mu \mathrm{m}$. To estimate the failure probability caused by the propagation of a crack from a natural defect, a linear elastic fracture mechanic approach is therefore proposed. As defined in Eq,14, according to LEFM and the Murakami approach [34], a defect of size $\sqrt{\text { area }}$, considered as a pre-existing crack will not propagate under cyclic loads if the applied stress intensity range, $\Delta K_{I}$, is less than 
the material crack propagation threshold, $\Delta K_{t h}$.

$$
\Delta K_{I}=0.65 \sigma_{a} \sqrt{\pi \sqrt{\text { area }}} \leq \Delta K_{t h}
$$

As for the intrinsic local fatigue resistance, the stochastic character of the long crack propagation threshold is modelled using a Weibull distribution [36, 37] for which the probability density function is given by:

$$
f_{02}\left(\Delta K_{t h}\right)=\frac{m_{2}}{\Delta K_{t h 0}}\left(\frac{\Delta K_{t h}}{\Delta K_{t h 0}}\right)^{m_{2}-1} \exp -\left(\frac{\Delta K_{t h}}{\Delta K_{t h 0}}\right)^{m_{2}}
$$

In this case, the shape factor or the Weibull exponent, $m_{2}$, governs the scatter and $\Delta K_{t h 0}$ is the scale factor of the distribution.

The probability of a crack propagating, corresponds to the probability that $\Delta K$ is above the material $\Delta K_{\text {th }}$ as expressed in $\mathrm{Eq}, 16$ :

$$
P_{F_{2}}=1-\exp \left[-\left(\frac{\Delta K_{I}}{\Delta K_{t h 0}}\right)^{m_{2}}\right]
$$

Assuming that all specimens with a natural defect at the initiation site broke when the stress intensity factor range reached the crack propagation threshold, the cumulative probability of the crack propagation threshold can be ploted (as in Fig[15). In this figure the two points with the lowest defect size locate on the Kitagawa-Takahashi plateau were not considered. Note that two data points in Fig.15 do not seem to follow the Weibull trend. These two data with a particular high crack propagation threshold were not taken into account to fit the Weibull distribution. The crack propagation threshold data presented in Fig. 15 are lower than the data found in the literature for wrought Ti-6Al-4V $\left(\Delta_{K t h}=5.6 \mathrm{MPa} \cdot \mathrm{m}^{1 / 2}\right.$ [40, 41] and LPBF Ti-6Al-4V $\left(\Delta_{K t h}=3.65 \mathrm{MPa} \cdot \mathrm{m}^{1 / 2}\right.$ [42]) material via $\mathrm{CT}$ specimens (obtained using a load ratio $\mathrm{R}=-1$ and without considering the load negative part for the $\Delta_{K t h}$ calculation ). It is well known in fatigue that the crack propagation threshold tend to decrease when the crack length becomes small. These low values, compare to CT propagation results for the long crack domain are probably due to the small defect size, being studied. The Weibull function parameters are $\Delta K_{t h 0}=2.33 \mathrm{MPa} \cdot \mathrm{m}^{1 / 2}$ and $m_{2}=13.49$. 


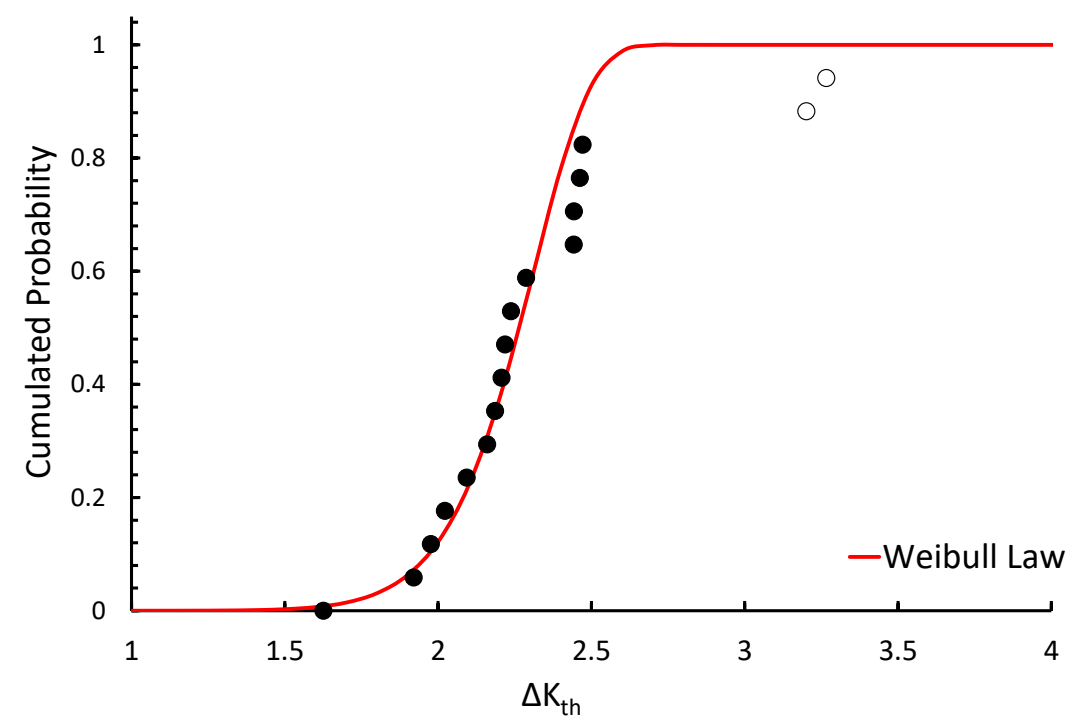

Fig. 15: $\Delta_{K t h}$ cumulative probabilty and Weibull function identified.

\subsubsection{Combined failure probability}

Finally, it is proposed that the survival probability of a volume $V_{\Omega}$, failing by one or the other damage scenarios, is equal to the product of the two survival probabilities described by Eq, 11 and Eq 16. Essentially, the weakest link hypothesis [38], is employed once again, which assumes that the two damage mechanisms are independent, leading to equation 17 .

$$
1-P_{F}=\left(1-P_{F_{1}}\right)\left(1-P_{F_{2}}\right)
$$

The combined probability of failure for a tested volume size $V_{\Omega}$ can thus be written as in equation 18 describing a bimodal Weibull distribution.:

$$
P_{F}=1-\exp \left\{-\left[\frac{V_{\Omega}}{V_{0}}\left(\frac{\sigma_{a}}{\sigma_{t h 0}}\right)^{m_{1}}+\left(\frac{F \sigma_{a} \sqrt{\pi \sqrt{\text { area }}}}{\Delta K_{t h 0}}\right)^{m_{2}}\right]\right\}
$$

The volume size effect on the microstructural fatigue strength is explicitly taken into account via the terms $\frac{V_{\Omega}}{V_{0}}$. In addition the defect size is directly introduced as an input parameter. The 
influence of the tested volume size on the probability of finding a large defect is not modelled.

Eq.18, plotted as a function of the defect size, $\sqrt{\text { area }}$, results in a probabilistic KitagawaTakahashi diagram as shown in Fig.16. The probabilistic approach correctly predict the fatigue strength trends experimentally observed. It also predict a decreasing critical defect size with a decreasing HSV.

As shown in Fig.16, care should be taken when using a deterministic Kitagawa-Takahashi diagram because it often neglects the volume or size effect on the fatigue plateau for small defects sizes. Particular care must be taken when the dimensioning curves are derived from tests carried out on small test specimens. The proposed approach is a first step to consider, at the same time, the fatigue strength sensitivity to the loaded volume size in presence of two different damage mechanisms (initiation with and without natural defects).

The comparison of the fatigue strength without natural defects to those obtained from Ti6AL-4V LPBF HIP and hot-rolled materials [13] illustrates the importance of better controlling the Ti-6AL-4V LPBF microstructre. According to the results obtained in this study, removing the natural defects (LoF, gaseous pore, etc.) would only have a limited impact on improving the fatigue resistance of Ti-6AL-4V LPBF. In the absence of a natural defect, the high sensitivity of the fatigue strength to the volume size illustrates significant microstructure variability which results in high scatter and a limited average value. In the absence of natural defects, the optimization of LPBF processes in order to guarantee a more homogeneous microstructures and less sensitive to the scale effect in fatigue is a challenge to be taken up to guarantee better resistance of Ti-6Al-4VLPBF components in fatigue.

\section{Conclusion}

This paper presents the results of a fatigue test campaign performed on Ti-6Al-4V manufactured by LPBF. The effect of the tested volume on the fatigue strength was investigated by introducing different numbers of hemispherical surface holes to locally raised the stress and change the 


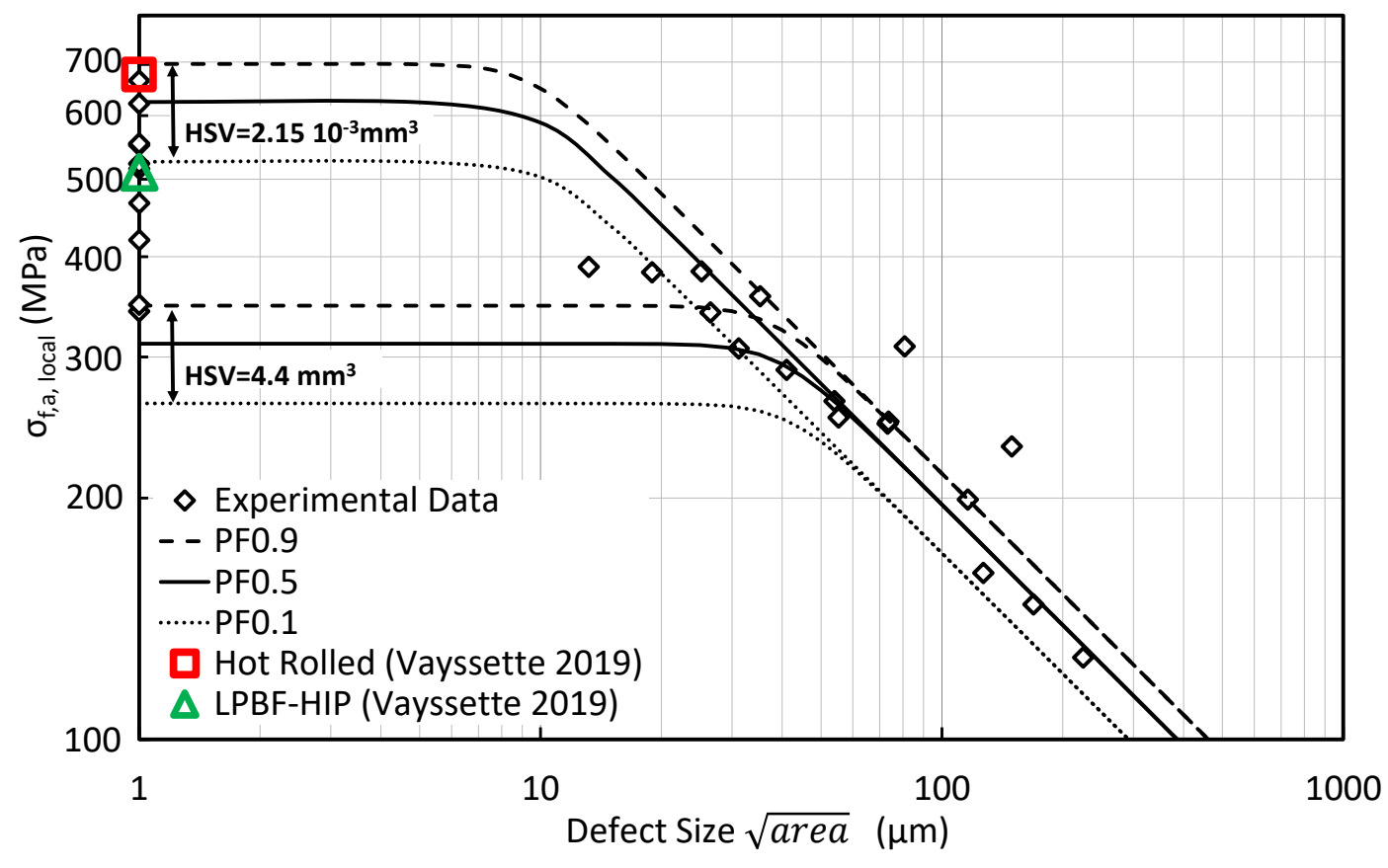

Fig. 16: Kitagawa-Takahashi diagram, corresponding to $\mathrm{Eq} 18$ for differents HSV and failure probabilities compared to litterture data [13].

size of the Highly Stressed Volume (HSV). For specimens with small highly stressed volumes it was possible to characterize the material fatigue strength without pores.

The following conclusions can be drawn from the result analysis:

- In the absence of pores in the HSV, the material fatigue strength ranges from 342 to 663 MPa and is very sensitive to the HSV size.

- The critical defect size affecting the fatigue strength of the LPBF Ti-6Al-4V is approximately $30 \mu \mathrm{m}$ for push-pull loads and fatigue life of $10^{6}$ cycles.

- When a crack initiates from a pore, the fatigue strength decreases with the increasing size of the HSV. This can be explained by the direct relationship between the probability of finding 
a large defect and the size of the tested volume.

- The fatigue sensitivity to the defect size is correctly predicted using a linear elastic fracture mechanic approach, in crack opening mode I and the Murakami defect size parameter $\sqrt{\text { area }}$.

- A probabilistic approach, based on the size effect is proposed to predict the occurence of crack initiation from a microstructure feature or from a natural defects.

\section{References}

[1] L. Bian, S. M. Thompson, N. Shamsaei, Mechanical properties and microstructural features of direct laserdeposited ti-6al-4v, JOM 67 (3) (2015) 629-638. doi:10.1007/s11837-015-1308-9

[2] H. K. Rafi, T. L. Starr, B. E. Stucker, A comparison of the tensile, fatigue, and fracture behavior of ti-6al-4v and 15-5 PH stainless steel parts made by selective laser melting, The International Journal of Advanced Manufacturing Technology 69 (5-8) (2013) 1299-1309. doi:10.1007/s00170-013-5106-7.

[3] L. Facchini, E. Magalini, P. Robotti, A. Molinari, S. Höges, K. Wissenbach, Ductility of a ti-6al-4v alloy produced by selective laser melting of prealloyed powders, Rapid Prototyping Journal 16 (6) (2010) 450-459. doi:10.1108/13552541011083371.

[4] V.-D. Le, E. Pessard, F. Morel, F. Edy, Interpretation of the fatigue anisotropy of additively manufactured ta6v alloys via a fracture mechanics approach. Engineering Fracture Mechanics 214 (2019) 410-426, cited By 0. doi:10.1016/j.engfracmech.2019.03.048 URL https://www . scopus.com/inward/record.uri?eid=2-s2.0-85063737124\&doi=10.1016\%2fj . engfracmech.2019.03.048\&partnerID=40\&md5=ca6bedb3439395a3747377debb824269

[5] J. Günther, D. Krewerth, T. Lippmann, S. Leuders, T. Tröster, A. Weidner, H. Biermann, T. Niendorf, Fatigue life of additively manufactured ti-6al-4v in the very high cycle fatigue regime, International Journal of Fatigue 94 (2017) 236-245. doi:10.1016/j.ijfatigue. 2016.05.018

[6] D. Greitemeier, F. Palm, F. Syassen, T. Melz, Fatigue performance of additive manufactured TiAl6v4 using electron and laser beam melting, International Journal of Fatigue 94 (2017) 211-217. doi:10.1016/j. ijfatigue.2016.05.001

[7] Y. Kok, X. Tan, P. Wang, M. Nai, N. Loh, E. Liu, S. Tor, Anisotropy and heterogeneity of microstructure and mechanical properties in metal additive manufacturing: A critical review, Materials and Design 139 (2018) 565586, cited By 170. doi:10.1016/j.matdes .2017.11.021. URL https://www. scopus. com/inward/record.uri?eid=2-s2.0-85036472857\&doi=10.1016\%2fj . matdes . 2017. 11.021\&partner ID=40\&md5=5c2e5f384c4337627701d55da697dec2 
[8] A. Fatemi, R. Molaei, S. Sharifimehr, N. Phan, N. Shamsaei, Multiaxial fatigue behavior of wrought and additive manufactured ti-6al-4v including surface finish effect, International Journal of Fatigue 100 (2017) 347-366. doi:10.1016/j.ijfatigue.2017.03.044

[9] A. Fatemi, R. Molaei, S. Sharifimehr, N. Shamsaei, N. Phan, Torsional fatigue behavior of wrought and additive manufactured ti-6al-4v by powder bed fusion including surface finish effect, International Journal of Fatigue 99 (2017) 187-201. doi:10.1016/j.ijfatigue.2017.03.002

[10] E. Wycisk, A. Solbach, S. Siddique, D. Herzog, F. Walther, C. Emmelmann, Effects of defects in laser additive manufactured ti-6al-4v on fatigue properties, Physics Procedia 56 (2014) 371-378. doi:10.1016/j .phpro. 2014.08 .120

[11] E. Wycisk, S. Siddique, D. Herzog, F. Walther, C. Emmelmann, Fatigue performance of laser additive manufactured ti-6al-4v in very high cycle fatigue regime up to 109 cycles. Frontiers in Materials 2 , cited By 40 (2015). doi:10.3389/fmats.2015.00072.

URL https://www.scopus.com/inward/record.uri?eid=2-s2.0-84991536462\&doi=10.3389\% 2ffmats. 2015.00072\&partnerID=40\&md5=d11ac275cd8b18807a6e67376fbf 9302

[12] V. Chastand, P. Quaegebeur, W. Maia, E. Charkaluk, Comparative study of fatigue properties of ti-6al-4v specimens built by electron beam melting (ebm) and selective laser melting (slm), Materials Characterization 143 (2018) 76-81, cited By 13. doi:10.1016/j.matchar.2018.03.028.

URL https://www . scopus . com/inward/record.uri?eid=2-s2.0-85053821679\&doi=10.1016\%2fj . matchar . 2018.03.028\&partnerID=40\&md5=b302fa0e425ff $1 \mathrm{~b} 26038 \mathrm{~b} 1 \mathrm{f} 1 \mathrm{c} 7 \mathrm{e} 048 \mathrm{ef}$

[13] B. Vayssette, N. Saintier, C. Brugger, M. El May, E. Pessard, Numerical modelling of surface roughness effect on the fatigue behavior of ti-6al-4v obtained by additive manufacturing, International Journal of Fatigue 123 (2019) 180-195, cited By 2. doi:10.1016/j.ijfatigue.2019.02.014.

URL https://www.scopus.com/inward/record.uri?eid=2-s2.0-85061939901\&doi=10.1016\%2fj . ijfatigue. 2019.02.014\&partner ID=40\&md5=4140990586e94cb1e59b1f c80370d030

[14] F. Cao, T. Zhang, M. Ryder, D. Lados, A review of the fatigue properties of additively manufactured ti-6al-4v, JOM 70 (3) (2018) 349-357, cited By 13. doi:10.1007/s11837-017-2728-5.

URL https://www.scopus.com/inward/record.uri?eid=2-s2.0-85042208377\&doi=10.1007\% 2f s11837-017-2728-5\&partnerID=40\&md5=8bcfdf 46c04cb937c3e1ee666127abc9

[15] R. Pogoretskii, Effect of test piece length on the fatigue strength of steel in air, Soviet Materials Science 1 (1) (1966) 63-66, cited By 2. doi:10.1007/BF00714989

URL https://www.scopus.com/inward/record.uri?eid=2-s2.0-34250537841\&doi=10.1007\% 2fBF00714989\&partnerID=40\&md5=a2ef46e0b698059d7dc5e47376060011

[16] S. Beretta, A. Blarasin, M. Endo, T. Giunti, Y. Murakami, Defect tolerant design of automotive components, International Journal of Fatigue 19 (4) (1997) 319-333, cited By 59. doi:10.1016/S0142-1123(96) 00079-5. 
URL https://www.scopus.com/inward/record.uri?eid=2-s2.0-0031122782\&doi=10.1016\% 2fS0142-1123\%2896\%2900079-5\&partnerID=40\&md5=8b376c24f941d708d1f00a76dcc4e741

[17] S.Beretta, Y.Murakami, Sif and threshold for small cracks at small notches under torsion, Fatigue and Fracture of Engineering Materials and Structures 23 (2) (2000) 97-104. doi:10.1046/j .1460-2695.2000.00260.x. URL http://dx.doi.org/10.1046/j.1460-2695.2000.00260.x

[18] Y. Ai, S. Zhu, D. Liao, J. Correia, C. Souto, A. De Jesus, B. Keshtegar, Probabilistic modeling of fatigue life distribution and size effect of components with random defects, International Journal of Fatigue 126 (2019) 165-173, cited By 16. doi:10.1016/j.ijfatigue.2019.05.005 URL https://www. scopus.com/inward/record.uri?eid=2-s2.0-85065452247\&doi=10.1016\%2fj . ijfatigue. 2019.05.005\&partner ID=40\&md5=e354853dc2c4978ece1c3c30561bdc98

[19] D. El Khoukhi, F. Morel, N. Saintier, D. Bellett, P. Osmond, V.-D. Le, J. Adrien, Experimental investigation of the size effect in high cycle fatigue: Role of the defect population in cast aluminium alloys, International Journal of Fatigue 129, cited By 0 (2019). doi:10.1016/j.ijfatigue.2019.105222

URL https://www .scopus . com/inward/record.uri?eid=2-s2.0-85071134005\&doi=10.1016\%2fj . ijfatigue. 2019.105222\&partner ID=40\&md5=2714e598ecff8ed89b47fb7e06c26f3f

[20] F. Abroug, E. Pessard, G. Germain, F. Morel, Hcf of aa7050 alloy containing surface defects: Study of the statistical size effect, International Journal of Fatigue 110 (2018) 81-94, cited By 3. doi:10.1016/j.ijfatigue. 2018.01 .012

URL https://www.scopus. com/inward/record.uri?eid=2-s2.0-85041470159\&doi=10.1016\%2fj . ijfatigue. 2018.01.012\&partnerID=40\&md5=837135e41b18997a584d535408938036

[21] Y. Hu, S. Wu, Z. Wu, X. Zhong, S. Ahmed, S. Karabal, X. Xiao, H. Zhang, P. Withers, A new approach to correlate the defect population with the fatigue life of selective laser melted ti-6al-4v alloy, International Journal of Fatigue 136, cited By 4 (2020). doi:10.1016/j . ijfatigue.2020.105584 URL https://www . scopus . com/inward/record.uri?eid=2-s2.0-85081620124\&doi=10.1016\%2fj . ijfatigue. 2020.105584\&partner ID=40\&md5=40772620d0531faeb8c1b94c5d83ee58

[22] T. S. Kitagawa H, Applicability of fracture mechanics to very small cracks, in: ASM Proceedings of 2nd international conference on mechanical Metalspark, Ohio, 1976, pp. 627-631.

[23] A. International, ASTM F3001-14, Standard Specification for Additive Manufacturing Titanium-6 Aluminum-4 Vanadium ELI (Extra Low Interstitial) with Powder Bed FusionCited By 5 (2014).

[24] Fatigue and fracture mechanics, Vol. 29 of ASTM SPECIAL TECHNICAL PUBLICATION// STP, ASTM, 1999.

URL https://books .google.fr/books?id=Vqkrnp825HQC

[25] Murakami, Uemura, Natsume, Miyakawa, Effect of mean stress on the fatigue strength of high-strength steels containing small defects or nonmetallic inclusions, Trans. Jpn Soc. Mech. Eng. A (56) (1990) 1074-1081. 
[26] O. Andreau, E. Pessard, I. Koutiri, J.-D. Penot, C. Dupuy, N. Saintier, P. Peyre, A competition between the contour and hatching zones on the high cycle fatigue behaviour of a 3161 stainless steel: Analyzed using x-ray computed tomography, Materials Science and Engineering A 757 (2019) 146-159, cited By 2. doi:10.1016/j.msea.2019.04.101

1 URL https://www.scopus.com/inward/record.uri?eid=2-s2.0-85065124172\&doi=10.1016\%2fj. msea $\cdot 2019.04 .101 \&$ partner ID $=40 \& m d 5=22227 d 59238 \mathrm{bf} 682 \mathrm{dd} 266 \mathrm{cf} \mathrm{c} 2 \mathrm{f} 163 \mathrm{ebf}$

[27] Z. Xu, A. Liu, X. Wang, The influence of building direction on the fatigue crack propagation behavior of ti6al4v alloy produced by selective laser melting, Materials Science and Engineering A 767, cited By 0 (2019). doi:10.1016/j.msea.2019.138409

URL https://www.scopus.com/inward/record.uri?eid=2-s2.0-85072222975\&doi=10.1016\%2fj . msea $.2019 .138409 \&$ partner ID $=40 \& m d 5=6 f c 753 c 1 c 2439 b b 3 d b 5 f 70088 d 1 f c 896$

[28] B. Ellyson, M. Brochu, M. Brochu, Characterization of bending vibration fatigue of slm fabricated ti-6al-4v, International Journal of Fatigue 99 (2017) 25-34, cited By 14. doi:10.1016/j.ijfatigue.2017.02.005 URL https://www.scopus.com/inward/record.uri?eid=2-s2.0-85013485363\&doi=10.1016\%2f j. ijfatigue . 2017.02.005\&partnerID=40\&md5=a63258c9e762d134e5fc40a84dfd9320

[29] D. Lanning, T. Nicholas, G. Haritos, On the use of critical distance theories for the prediction of the high cycle fatigue limit stress in notched ti-6al-4v, International Journal of Fatigue 27 (1) (2005) 45-57, cited By 84. doi:10.1016/j.ijfatigue.2004.06.002

URL https://www.scopus.com/inward/record.uri?eid=2-s2.0-7444265835\&doi=10.1016\%2fj. ijfatigue . 2004.06.002\&partnerID $=40 \& m d 5=d 606102 d 78 \mathrm{a} 4 \mathrm{a} 8 \mathrm{f} 0 \mathrm{f} 47 \mathrm{a} 891 \mathrm{be} 0 \mathrm{~b} 98763$

[30] ASTM International, West Conshohocken, PA, Standard Test Method for Measurement of Fatigue Crack Growth Rates (2015).

[31] C. Sonsino, H. Kaufmann, V. Grubišić, Transferability of material data for the example of a randomly loaded forged truck stub axle, SAE Technical PapersCited By 25 (1997). doi:10.4271/970708

URL https://www.scopus.com/inward/record.uri?eid=2-s2.0-85072464298\&doi=10.4271\% 2f970708\&partnerID=40\&md5=9df 9be19598d8f 876 daa635eb5da9f 82

[32] B. Ellyson, N. Chekir, M. Brochu, M. Brochu, Characterization of bending vibration fatigue of wbd fabricated ti-6al-4v, International Journal of Fatigue 101 (2017) 36-44, cited By 4. doi:10.1016/j.ijfatigue. 2017. 03.045

URL https://www.scopus.com/inward/record.uri?eid=2-s2.0-85018584487\&doi=10.1016\%2fj. ijfatigue . 2017.03.045\&partnerID $=40 \& m d 5=637008 \mathrm{cab} 29502 \mathrm{f} 985 \mathrm{a} 5145 \mathrm{ac} 021 \mathrm{~b} 8 \mathrm{f} 6$

[33] M. Neikter, P. Åkerfeldt, R. Pederson, M.-L. Antti, V. Sandell, Microstructural characterization and comparison of ti-6al-4v manufactured with different additive manufacturing processes, Materials Characterization 143 (2018) 68-75, cited By 18. doi:10.1016/j.matchar.2018.02.003. 
URL https://www.scopus.com/inward/record.uri?eid=2-s2.0-85042273976\&doi=10.1016\%2fj . matchar . 2018.02.003\&partnerID=40\&md5=70388a1727ae579f ad3ebb4a277de8d5

[34] Y. Murakami, Effects of small defects and nonmetallic inclusions, Elsevier, 2002.

[35] L. Makkonen, R. Rabb, M. Tikanmäki, Size effect in fatigue based on the extreme value distribution of defects, Materials Science and Engineering: A 594 (0) (2014) 68 - 71. doi:http://dx.doi.org/10.1016/j.msea. 2013.11 .045

URL http://www.sciencedirect.com/science/article/pii/S0921509313012732

[36] W. Weibull, A Statistical Theory of the Strength of Materials, Generalstabens litografiska anstalts förlag, 1939.

[37] W. Weibull, A statistical distribution function of wide applicability, Journal of Applied Mechanics 18 (1951) 293-297.

[38] A. Freudenthal, in: H. Liebowitz (Eds.) Fracture vol 2 (1968) 591-619. doi : 10.1016/j . engfracmech. 2019. 03.048

[39] M. Abramowitz, A. Stegun, Handbook of Mathematical Functions, Dover, New York, 1965.

[40] S. Stanzl-Tschegg, Fatigue crack growth and thresholds at ultrasonic frequencies. International Journal of Fatigue 28 (11) (2006) 1456-1464, cited By 37. doi:10.1016/j.ijfatigue.2005.06.058 URL https://www. scopus . com/inward/record.uri?eid=2-s2.0-33746381497\&doi=10.1016\%2fj . ijfatigue. 2005.06.058\&partnerID=40\&md5=29abbd067f1b70c37d942046e36862a7

[41] C. Santus, D. Taylor, Physically short crack propagation in metals during high cycle fatigue, International Journal of Fatigue 31 (8-9) (2009) 1356-1365, cited By 72. doi:10.1016/j.ijfatigue.2009.03.002 URL https://www . scopus. com/inward/record.uri?eid=2-s2.0-67349256412\&doi=10.1016\%2f j. ijfatigue.2009.03.002\&partnerID=40\&md5=39be9cc9f9fefd1785752fc560afd96b

[42] M. Benedetti, C. Santus, Notch fatigue and crack growth resistance of ti-6al-4v eli additively manufactured via selective laser melting: A critical distance approach to defect sensitivity. International Journal of Fatigue 121 (2019) 281-292, cited By 7. doi:10.1016/j.ijfatigue.2018.12.020

URL https://www.scopus.com/inward/record.uri?eid=2-s2.0-85060342009\&doi=10.1016\%2fj . ijfatigue . 2018.12.020\&partnerID=40\&md5=f7bedd6745c12f944f043e0990652b85 